\title{
REGIONALISMO EN ASIA CENTRAL: UN BALANCE
}

Paulo Duarte

\section{INTRODUCCIÓN}

ESTE ARTÍCULO BUSCA ILUSTRAR las principales características del regionalismo en Asia Central. El argumento principal es que el regionalismo, como lo practican las repúblicas asiáticas centrales, ha resultado ser un tanto tímido, ya que ha tenido poco efecto y no ha contribuido de manera significativa a la integración regional. Para que dicha integración ocurra, es necesario que las repúblicas asiáticas centrales adopten una postura de mayor cooperación, lo que implica ampliar la importancia de las organizaciones multilaterales existentes en la región.

Al contrario de la noción realista de que los Estados son "los únicos actores importantes" y que "actúan como unidades coherentes”, las teorías de multilateralismo, transnacionalismo, institucionalismo e interdependencia nos ayudan a comprender que las organizaciones internacionales deben ser consideradas para el estudio de la interacción entre actores. ${ }^{1} \mathrm{E}$ lanálisis hermenéutico es un medio excelente para esto, ya que se centra en significados normativos. La actividad social asume la existencia de reglas constitutivas y regulatorias, tan preciadas por Winch y Wittgenstein, para las rutinas y los principios que rigen la conducta de los distintos actores, lo que permite adoptar una postura interpretativa. En otras

${ }^{1}$ John Ruggie, "Epistemology, Ontology, and the Study of International Regimes", Constructing the World Polity: Essays on International Institutionalization, Londres-Nueva York, Routledge, 1998, p. 42. 
palabras, la acción no puede ser separada de "contextos funcionales", aunque estos "no existen separados de configuraciones particulares de actores y su reacción ante asuntos específicos: los diferentes objetivos de actores varios, por los que se lucha con recursos repartidos de forma desigual, definen los "contextos funcionales". ${ }^{2} \mathrm{Al}$ supuesto realista de anarquía en el ámbito internacional, en el cual los derechos y deberes objetivos no existen, por lo que nadie tiene facultades para nada, oponemos un supuesto diferente que destaca reglas e instituciones, y que además recurre a una concepción constructivista que será explicada a continuación.

Buscaremos describir la operación de cinco organizaciones regionales cuyo objetivo es promover la operación e integración regional en Asia Central: la Organización de Cooperación de Shanghái, la Organización de Cooperación Económica, la Organización del Tratado de la Seguridad Colectiva, la Comunidad de Estados Independientes y la Comunidad Económica Eurasiática. Dichas organizaciones han tenido un impacto pequeño en la integración regional. Han demostrado ser "organizaciones más enfocadas hacia la consulta que hacia la realización de proyectos regionales". ${ }^{3}$ En vez de técnicas de observación de participantes y no-participantes, difíciles de aplicar a este objeto de estudio, recurrimos a entrevistas semiestructuradas. ${ }^{4}$ Optamos por recurrir a expertos de organizaciones no gubernamentales haciendo trabajo de campo, y también a personal de embajadas en las repúblicas asiáticas centrales, entre otros agentes. Otros entrevistados eran de las repúblicas asiáticas centrales en cuestión. ${ }^{5}$ Algunos entrevistados

${ }^{2}$ Ibid., p. 46.

${ }^{3}$ Chinara Esengul, The Politics of Regionalism in Central Asia, Ministerio de Ciencia y Educación de la República de Kirguistán, Universidad Nacional Kirguís Jusup Balasagyn, 2009, p. 9.

${ }^{4}$ Creemos que la entrevista semiestructurada es el método más pertinente para el problema de investigación, porque privilegia conocimiento local, i.e. conocimiento con base en experiencia de campo, por individuos residentes del área o las áreas en las que se enfoca la investigación.

${ }^{5}$ Pensamos que esta variedad de entrevistas es capaz de ofrecer puntos de vista diversos sobre el tema que estudiamos. Además, entrevistar funcionarios de embajadas y gente local provee, por un lado, la perspectiva exterior de personas ajenas a la región sobre los locales y, por el otro, la perspectiva de los propios asiá- 
en Asia Central pidieron anonimato o, en algunos casos, solicitaron ser referidos como expertos locales, conectados a la diplomacia estadounidense en Kazajistán y Kirguistán. Una parte de la investigación de campo se hizo mediante entrevistas en Portugal, pero la mayoría de las entrevistas se hicieron en Asia Central a individuos clave relacionados con el tema de estudio. Se observó a los demás actores mediante entrevistas personales en un viaje a Portugal y dos viajes a Asia Central. El primer viaje fue del 3 al 11 de septiembre de 2011 a Kazajistán, bajo invitación del Director del Instituto Suleimenov, en Almaty. El segundo viaje fue del 28 de septiembre al 18 de octubre 2012 a dos países además de Kazajistán: Kirguistán y Tayikistán (entre las ciudades visitadas que podemos destacar están Almaty, Biskek, Naryn, Osh y Dusambé) ${ }^{6}$

Aunque no desechamos los postulados realistas y neorrealistas en su referencia a la cooperación y sus obstáculos en Asia Central, creemos que estos postulados no pueden ni deben ser entendidos como hechos absolutos e incuestionables, en la medida en que podría haber espacios (y efectivamente los hay) para la cooperación, aun si hasta ahora ha sido tímida. El realismo como postulado subyacente a los intereses de los Estados es insuficiente para analizar el comportamiento de los actores y las dinámicas del "New Great Game", ${ }^{7}$ porque hay algo más allá de la racionalidad, lo que presupone la adopción metodológica de una hermenéutica.

ticos centrales sobre la realidad geográfica, cultural, económica, política y social en la que viven.

${ }^{6}$ La planeación de los dos viajes a Asia Central implicó un trabajo de investigación profundo, y que llevó mucho tiempo, sobre universidades, expertos, diplomáticos, profesores y organizaciones no gubernamentales. La Red Aga Khan, entre muchos otros actores, proveyó un apoyo considerable, no sólo en términos de la selección de expertos locales, sino en permitir entrevistas a distancia por teléfono y visitas a varias áreas de la Universidad de Asia Central (en Kazajistán, Kirguistán y Tayikistán).

${ }^{7}$ El concepto de "New Great Game" se refiere a "revivir" el "Great Game" que opuso a los imperios británico y ruso, aunque hoy tenga contornos diferentes que involucran una "diplomacia del petróleo" con una política de seguridad y defensa integrada. 
En efecto, la concepción realista de "lucha por el poder" 8 competencia en Asia Central, presentada por lo general como "casi irreversible" es, en nuestra opinión, reduccionista: los "juegos" en que se involucran las naciones tienen una dinámica de cooperación y conflicto que requieren afinar la postura realista. Esto se logra recurriendo a una teoría más completa y moderada para la comprensión de la realidad, a la manera de una vía media como la que ofrece el constructivismo.

Aunque los beneficios de la integración y la cooperación económicas a nivel regional sean significativos para Asia Central, hay varios obstáculos políticos y de gobierno para obtenerlos. Como dice Linn, "en el ámbito político, todos los líderes de los jóvenes Estados de Asia Central tienen en alta estima la soberanía de sus países, al mismo tiempo que algunos de ellos compiten por el control de los recursos -en especial el agua y la energía (Tayikistán y Uzbekistán) - o por la supremacía en el liderazgo regional (Kazajistán y Uzbekistán), mientras que otros prefieren operar en estricta neutralidad hasta el punto del aislamiento (Turkmenistán)". ${ }^{9}$ En consecuencia, examinaremos cómo los recursos de agua, petróleo y gas contribuyen a los débiles resultados de la cooperación multilateral. Por el momento es posible anticipar, siguiendo a Roy Allison, que "el regionalismo no es un enfoque prometedor para mitigar y contener conflictos en la mayoría de las circunstancias fuera de Europa". ${ }^{10}$ Para el caso de Asia Central, Allison afirma claramente que "es improbable que el ámbito regional sea un actor principal en futuras crisis de seguridad serias". ${ }^{11}$

Continuemos con una breve definición y discusión sobre lo que es Asia Central. A pesar de las diversas definiciones e interpretaciones del término "Asia Central”, en este artículo se considera

${ }^{8}$ Hans Morgenthau, Politics Among Nations: The Struggle for Power and Peace, Nueva York, Alfred A. Knopf, 1948.

${ }^{9}$ Johannes Linn, "Central Asian Regional Integration and Cooperation: Reality or Mirage?”, en Evgeny Vinokurov (ed.), EDB Eurasian Integration Yearbook, Almaty, Eurasian Development Bank, 2012, p. 100.

${ }^{10}$ Roy Allison, "Regionalism, Regional Structures and Security Management in Central Asia”, International Affairs, vol. 80, núm. 3, 2004, p. 467.

${ }^{11}$ Loc. cit. 
la acepción que integra los cinco Estados de Asia Central pertenecientes a la Comunidad de Estados Independientes (CIs por sus siglas en inglés): Kazajistán, Kirguistán, Tayikistán, Turkmenistán y Uzbekistán.

Asia Central como un área “pivote” del planeta

En términos estrictos, Asia Central es una región que sólo empezó a ser analizada desde un punto de vista geopolítico y como campo de trabajo para investigadores occidentales desde 1991, a partir del colapso de la Unión Soviética. ${ }^{12} \mathrm{El}$ término "Asia Central" se refiere a un vasto conjunto histórico construido alrededor de varias subunidades, y forjado a partir de una amalgama de situaciones económicas, políticas y culturales, de procesos de identidad y de comunidades étnicas. Asia Central es un punto de reunión vital de intereses económicos, geopolíticos, religiosos y étnico-lingüísticos, lo que la hace una región dotada de una profundidad histórica extraordinaria, en el corazón de los grandes desafíos contemporáneos.

La división territorial y el estatus administrativo de las unidades que componen la región son evidencia de cierta heterogeneidad. La definición de Asia Central predominante en la actualidad, que la percibe como la suma de las repúblicas que fueron parte de la Unión Soviética (Kazajistán, Kirguistán, Uzbekistán, Tayikistán, Turkmenistán), se formó en la mitad del siglo veinte por la necesidad de distinguir estas cinco repúblicas asiáticas centrales. Poco después de la independencia, en 1993, "esta definición fue reconocida oficialmente por las repúblicas asiáticas centrales, así como por la comunidad internacional". ${ }^{13}$

Para la Unesco, Asia Central no es únicamente "las cinco repúblicas exsoviéticas (Turkmenistán, Kazajistán, Kirguistán, Uzbekistán y Tayikistán)"; también considera Afganistán, Mongolia, el oeste

12 Morgan Liu, "Central Asia in the Post-Cold War World", Annual Review of Anthropology, vol. 40, 2011, pp. 115-131.

${ }^{13}$ Hafeez Malik, Central Asia: Its Strategic Importance and Future Prospects, Nueva York, St. Martin's Press, 1994, p. 4. 
de China y varias partes de Pakistán, Irán y la India”. ${ }^{14}$ Nótese que a pesar de la heterogeneidad económica y política de la región, Asia Central es considerada una "entidad geopolítica”. Varios estudios postsoviéticos siguen limitando Asia Central a las cinco Repúblicas exsoviéticas: Kirguistán, Kazajistán, Tayikistán, Uzbekistán y Turkmenistán. Esta concepción deja fuera a las áreas nombradas anteriormente, aunque, como ya hemos dicho, están profundamente conectadas geográfica e históricamente. En la era soviética, se denominaba a esta región Sredniaia Aziya ${ }^{15}$ (expresión que, traducida, significa 'Asia media') refiriéndose a "Tayikistán, Turkmenistán, Kirguistán, Uzbekistán” y dejando fuera a Kazajistán. ${ }^{16}$

Entre los especialistas dedicados a la importancia geopolítica y geoestratégica de la región eurasiática, Halford Mackinder, Zbigniew Brzezinski y Nicholas Spykman merecen atención particular: contribuyeron a crear un enfoque original para entender los principios que rigen las estructuras regionales en el espacio geopolítico y geoeconómico eurasiático. Según Mackinder, el mundo está dividido en áreas aisladas, cada una con una función especial. Para este autor, el "macizo central" (en donde la tierra se acumula en Eurasia) funge como pivote de todas las transformaciones geopolíticas de dimensiones históricas dentro de esta "Isla mundo". Mackinder destaca que en el contexto de los procesos geopolíticos globales, Eurasia está en el corazón del mundo, con el "macizo central" ocupando el centro del continente eurasiático. La influencia de los postulados de Mackinder siguió siendo considerable aún después de la caída del pivote geopolítico que era la Unión Soviética. Como Mackinder, Brzezinksy también apoya el postulado de

${ }^{14}$ Samuel Asimov, "Description of the Project”, UNESCO History of Civilizations of Central Asia, 2001, en http://www.unesco.org/culture/asia/html_eng/ projet.htm, párr. 2.

${ }^{15}$ Es interesante notar que, mientras que los expertos occidentales usan el término "Asia Central", los autores rusos no han abandonado (todavía) la expresión "Asia Media”, aunque ahora, al contrario del pasado, este concepto incluye lo que hoy es Kazajistán. El hecho de que haya múltiples interpretaciones para el concepto de Asia Central atestigua la falta de consenso sobre la región.

${ }^{16}$ Martin Lewis y Kren Wigen, The Myth of Continents: A Critique of Metageography, Berkeley, University of California Press, 1997, p. 179. 
que "quien controla el 'macizo central' podrá controlar la Isla mundo y el planeta". ${ }^{17}$

La doctrina que desarrolló Mackinder inspiró a otros estrategas como Nicholas Spykman, un influyente politólogo estadounidense de la década de los cuarenta. A diferencia de Mackinder, Spykman no recalcaba la importancia del macizo central eurasiático, sino la importancia de la frontera eurasiática, es decir Europa Occidental, la cuenca del Pacífico y Medio Oriente. Según Spykman, quien controlara estas regiones sería capaz de contener cualquier poder emergente del corazón de la región. ${ }^{18}$

Bajo el nuevo atlas energético, Asia Central está localizada en una zona estratégica, con fuertes lazos hacia las regiones vecinas. Durante siglos, Asia Central ha sido el cruce de Eurasia, la intersección entre Este y Oeste, lo que la convierte en una región interesante. Es el punto de confluencia de cuatro civilizaciones que han controlado y han sido controladas por pueblos centro-asiáticos. La estructura económica de Asia Central, y sus características políticas, han estado marcadas por su localización geográfica, y más específicamente por "el difícil acceso a otras partes del mundo". ${ }^{19}$ Además, como menciona Xiaojie Xu, "la supervivencia de las repúblicas de Asia Central depende esencialmente del mantenimiento de varios corredores y enlaces". ${ }^{20}$ Estos corredores son de igual o mayor importancia que el potencial energético de la región porque se expanden en todas direcciones, conectando China, Rusia, Europa, la región del Cáucaso y el Océano Índico.

17 Zbigniew Brzezinski, The Grand Chessboard: American Primacy and Its Geostrategic Imperatives, Nueva York, Basic Books, 1997, p. 21.

18 Para este autor, mientras que el "pivote" de Mackinder no tenía un papel histórico independiente que desempeñar, la Rimland era la clave de la dominación mundial. En consecuencia, "El que controla la Rimland gobierna Eurasia, y quien gobierna Eurasia controla el mundo”. Nicholas Spykman, Estados Unidos frente al mundo, México, FCE, 1944, p. 43.

${ }^{19}$ Paulo Duarte, "China Looks to Central Asia”, Boletim Mundorama, núm. 63, 2012, párr. 3.

${ }^{20}$ Xiaojie Xu, Unlocking the Assets: Energy and the Future of Central Asia and the Caucasus Oil and Gas Linkages between Central Asia and China: A Geopolitical Perspective, The James A. Baker III. Institute for Public Policy of Rice University, 1999, p. 36 . 
Como explica Zhao Huasheng, Asia Central "es un parachoques entre los grandes poderes, aunque Rusia tiene relaciones especiales con los países de la región”. ${ }^{21}$ La competencia entre potencias por recursos energéticos se intensificó desde el inicio del siglo xxi, lo que contribuyó a rápidos aumentos en los precios de la energía y a delinear nuevos parámetros de seguridad energética. En este contexto, y como resultado de sus reservas energéticas, Asia Central "ha demostrado ser un área de competencia y rivalidad entre potencias”, lo que afecta la relación entre éstas y el balance de poder, lo cual influye en la "estructura internacional" que emergió en el mundo "posterior a la Guerra Fría”. ${ }^{22}$

Varios autores no dudan en asignar a Asia Central una posición prominente en el nuevo orden mundial. Si miramos la historia del petróleo, "Desde la década de los años setenta, la ambición general [de los países consumidores] a partir de los choques petroleros ha sido depender menos del Golfo Pérsico, ya que es una región altamente volátil. ${ }^{23}$ De hecho, como apunta Richard Ottinger, "buena parte de las reservas de petróleo que quedan están en los países inestables de Medio Oriente, lejos de las áreas de consumo", lo que provoca "preocupaciones sobre la seguridad de la oferta de petróleo". ${ }^{24}$ No obstante, se debe notar que la ambición de hallar "otro Golfo Pérsico" no ha ocurrido y probablemente nunca ocurra, ya que es casi imposible que otras regiones del mundo tengan las mismas reservas que Medio Oriente. Empero, en este mundo altamente competitivo, Asia Central y en particular la región del Caspio son de una importancia estratégica crucial para los recursos energéticos, si uno busca diversificar sus fuentes de suministro de energía.

${ }^{21}$ Huasheng Zhao, "Central Asia in China's Diplomacy," en Eugene B. Rumer, Dmitriy Trenin y Huasheng Zhao (eds.), Central Asia: The View from Washington, Moscow, and Beijing, Nueva York, M. E. Sharpe, 2007, p. 475.

${ }^{22}$ Duarte, op. cit, párr. 5.

${ }^{23}$ Pedro Fonseca, Entrevista personal, Lisboa, 2011. Pedro Fonseca is Professor of International Relations at ISCSP-Universidade de Lisboa.

${ }^{24}$ Richard Ottinger, UNEP Handbook for Drafting Laws on Energy Efficiency and Renewable Energy Resources, United Nations Environment Programme, 2007, p. 3. 
Según Guedes, "no es evidente que Asia Central sea un área provista de cohesión interna y distinguible de otras áreas que nos permita llamarla una 'región' (dentro del significado asignado al concepto de región por la relaciones internacionales)". ${ }^{25}$ Para este autor, esto se debe a que "una gran parte de Asia Central, en tanto región, tiene fronteras difusas y por lo general definidas en términos negativos". ${ }^{26}$ Asia Central es, para este autor, "una región de geometría variable, situada entre Rusia, la India, China, el mundo islámico y el Oeste" que corresponde, en cierta forma, a la vieja "Ruta de la seda". ${ }^{27}$ Asia Central no es, desde un punto de vista analítico, nada más que una denominación; no es un concepto.

\section{Organizaciones regionales en Asia Central}

Hagamos un breve apunte sobre organizaciones regionales. Según Alexander Wendt, el sistema internacional se construye a partir de estructuras sociales, en las cuales ideas e interacciones simbólicas definen la forma en que los Estados se relacionan entre ellos. ${ }^{28} \mathrm{En}$ consecuencia, las estructuras sistémicas están socialmente construidas y los intereses e identidades de los Estados están condicionados por estructuras sociales y viceversa. $\mathrm{Si}$, bajo un esquema constructivista, las reglas guían el comportamiento social, entonces las organizaciones internacionales son capaces de organizar acciones y esfuerzos conjuntos para que sus miembros lleguen a acuerdos más fácilmente. Las organizaciones internacionales operan "dentro de un espacio de políticas cuyos ejes se definen por los objetivos y los instrumentos del régimen que sirven”. ${ }^{29}$ Las organizaciones regionales, por su parte, existen para "promover mecanismos de cooperación entre Estados dispuestos a profundizar su pertenencia a un

25 Armando Guedes, Entrevista personal, Lisboa, 2011. Armando Marques Guedes es profesor de leyes en la Universidade Nova de Lisboa.

${ }^{26}$ Loc. cit.

${ }^{27}$ Loc. cit.

28 Alexander Wendt, "Anarchy Is what States Make of It: The Social Construction of Power Politics”, International Organisation, vol. 46, núm. 2, 1992.

${ }^{29}$ Ruggie, op. cit., p. 56. 
área geográfica, una entidad política o un bloque económico". ${ }^{30}$ En tanto agentes de la construcción social de la realidad, las organizaciones internacionales ayudan a seleccionar asuntos considerados críticos para la coexistencia entre Estados, que deben ser considerados colectivamente para evitar conflictos. El tema de las organizaciones regionales en Asia Central es uno de los puntos más debatidos en ámbitos políticos y académicos; las conclusiones difieren ampliamente: algunos destacan la falla total del regionalismo en Asia Central, otros recalcan el éxito de nuevos patrones de integración en la región.

\section{Organización de COOPERAGión de ShangháI}

\section{Orígenes y misión}

Según Peter Ferdinand, "la Organización de Cooperación de Shanghái es importante porque es el resultado de una iniciativa diplomática china y es la primera organización de su tipo en la cual China ha asumido el papel de líder". ${ }^{31}$ El Grupo Shanghái, creado en 1996, surgió como resultado del nuevo orden mundial provocado por el colapso de la Unión Soviética y el clima de incertidumbre en que ello derivó. El grupo, originalmente compuesto por "China, Rusia, Kazajistán, Kirguistán y Tayikistán”, incorporó a Uzbekistán en el verano de 2001, tomando el nombre de "Organización de Cooperación de Shanghái” (sco por sus siglas en inglés). ${ }^{32}$ Destacando que no tenían intenciones de desafiar a Estados Unidos o a ningún otro Estado, los miembros aclararon que su cooperación tenía por único objetivo contribuir a la seguridad en la región. En

${ }^{30}$ Marlène Laruelle y Sébastien Peyrouse, "The Chinese Question in Central Asia: Domestic Order, Social Change, and the Chinese Factor", 2012, en http:/ /cup. columbia.edu/book/978-0-231-70304-8/the-chinese-question-in-central-asia, p. 5.

${ }^{31}$ Peter Ferdinand, "Sunset, Sunrise: China and Russia Construct a New Relationship”, International Affairs, vol. 83, núm. 5, 2007, p. 855.

${ }^{32}$ Michael Clarke, Bloomberg BusinessWeek, 26 de mayo de 2010, en http:/ / www.businessweek.com/stories/2010-05-26/chinas-deepening-ties-with-central-asiabusinessweek-business-news-stock-market-and-financial-advice\#disqus_thread, p. 4. 
consecuencia, se debe considerar a la sco no como un polo "antioccidental", sino como un polo "no-occidental"; 33 son, después de todo, dos realidades completamente distintas. No obstante, como observa Peter Ferdinand, "su colaboración diplomática es en parte una reacción en contra de la expansión de la OTAN hacia el Este y los desafíos de largo plazo que esto puede conllevar". ${ }^{34}$

Según Gene Germanovich, "la investigación occidental actual sobre la Organización de Cooperación de Shanghái tiene tres escuelas de pensamiento". ${ }^{35}$ La primera delinea una perspectiva negativa sobre el futuro de la sco y sus implicaciones para los intereses de Estados Unidos en Asia Central. Un defensor prominente de esta corriente de pensamiento es Stephen Blank (del Army War College de Estados Unidos). La utilidad de la sco para Rusia y China va más allá de ejercicios militares, tomando en consideración que Moscú y Beijing la han visto "desde su origen" como "un foro para unificar los gobiernos de Asia Central alrededor de una organización regional de seguridad antiestadounidense". ${ }^{36}$ Aunque esta corriente usualmente no "menciona iniciativas concretas de la sco (más allá de retórica y declaraciones) contra los intereses de Estados Unidos en la región", especula que "Rusia y China utilizan cumbres y sedes multilaterales como mecanismos para presionar a los Estados pequeños hacia posturas antiestadounidenses". ${ }^{37}$ Julia Nanay, analista de PFC Energy, cree que Rusia y China pueden llegar a desarrollar un grupo militar eurasiático bajo los auspicios de la Organización de Cooperación de Shanghái, como contrapeso para la OTAN. ${ }^{38}$

33 Isabel Facon, Les relations stratégiques Chine-Russie en 2005: la réactivation d'une amitié pragmatique, Fondation pour la Recherche Stratégique, 2006, p. 3.

${ }^{34}$ Ferdinand, op. cit., p. 855.

35 Gene Germanovich, "The Shanghai Cooperation Organisation: A Threat to American Interests in Central Asia?”, China and Eurasia Forum Quarterly, vol. 6, núm. 1, 2008, p. 21.

36 Stephen Blank, "U.S. Interest in Central Asia and Their Challenges", Demokratizatsiya, abril de 2007, p. 318.

${ }^{37}$ Germanovich, op. cit., pp. 21-22.

${ }^{38}$ Julia Nanay, "Inside Track: sco Gaining Importance", The National Interest online, 8 de agosto de 2007 . 
La segunda escuela de pensamiento argumenta que la sco "no es para nada una amenaza" hacia los intereses de Estados Unidos en Asia Central. ${ }^{39}$ Donald Rumsfeld dijo que el ejercicio PeaceMission de la sco en 2005, que involucró 10000 tropas, no representaba motivo de preocupación: "Los países hacen eso [...] Estamos obviamente observando qué sucede, pero no veo nada en ello que sea amenazante". ${ }^{40}$ Al preguntársele si Estados Unidos debía temer una alianza militar y económica dentro de la sco, Stephen Blank ${ }^{41}$ argumentó que "esto no es una organización antiestadounidense". ${ }^{42} \mathrm{El}$ autor admite que "aunque la SCO se opone a los intentos de Estados Unidos de promover un clima de reformas en Asia Central”, "apoya la presencia de los Estados Unidos en Afganistán”, otorgando "mucho dinero a este objetivo". ${ }^{3}$ Otro experto, quien pidió anonimato, cree que la sco no tiene una agenda antiestadounidense particular. Según este experto, la sco es "un intento de los chinos por ganar influencia en la región”. La tercera línea de pensamiento sugiere que "se necesita más tiempo para que los observadores interesados determinen qué rumbo tomará la sco". ${ }^{44}$ No destaca ninguno de los principales defensores de este argumento. Incluso, según Evan Feigenbaum, en Estados Unidos no hay una noción clara sobre lo que es y hace la Organización de Cooperación de Shanghái. ${ }^{45}$

Cualesquiera que sean sus intenciones verdaderas (más allá de sutilezas semánticas sobre lo "no-occidental" y lo "anti-occidental), la sco es un grupo de tipo "no-fijo”, grupo "vago" donde ningún

${ }^{39}$ Germanovich, op. cit., p. 22.

${ }^{40}$ Donald Rumsfeld, "China-Russia drill no threat”, China Daily, 2005, en http:/ / www.chinadaily.com.cn/english/doc/2005-08/25/content_472093.htm, p. 4.

${ }^{41}$ Stephen Blank es un experto del Instituto de Estudios Estratégicos del U.S. Army College.

${ }^{42}$ Stephen Blank, Entrevista personal, Estados Unidos, 2011.

${ }^{43}$ Loc. cit.

${ }^{44}$ Germanovich, op. cit., p. 22.

45 Evan Feigenbaum, "The Shanghai Cooperation Organization and the Future of Central Asia”, The Nixon Center, Washington, 2007, en http://2001-2009. state.gov/p/sca/rls/rm/2007/91858.htm 
miembro tiene la obligación de prestar ayuda a otro miembro bajo agresión militar. ${ }^{46}$ Esto explica la imposibilidad, al menos en el corto plazo, de que el grupo actúe como una entidad homogénea, por las diferentes prioridades que sus miembros dan a objetivos individuales. La sco es un instrumento evolutivo. Según Thierry Kellner, el debate entre los miembros se ha expandido progresivamente para incluir asuntos de seguridad, tomados no sólo en el sentido tradicional, sino también en un contexto más amplio. ${ }^{47}$ Es por ello que los miembros debaten riesgos asociados con el radicalismo islámico, el terrorismo y el tráfico de drogas. Los miembros de la sco han discutido recientemente otros asuntos como problemas ambientales y económicos, así como asuntos culturales. ${ }^{48}$ Pero a pesar de todos los cambios que ha tenido la organización, debemos afirmar que sus objetivos permanecen inalterados. ${ }^{49}$

\section{La eficiencia institucional de la Organización de Cooperación de Shanghái}

En un contexto rebosante de "múltiples organizaciones" con "ineficiencias masivas", y dado que "la operación de estas organizaciones es el blanco de intentos de control por la Federación Rusa”, en la opinión de expertos como Raquel Freire se puede considerar a la sco como un caso de "algún éxito". ${ }^{50}$ No obstante,

${ }^{46}$ David Hoffman, Entrevista personal, Almaty, 2011. David Hoffman es agregado del Consulado de Estados Unidos en Almaty.

47 Thierry Kellner, "La Chine et la Nouvelle Asie Centrale", Rapport du GRIP 2002 / 1, Bruxelles, en http:/ /www.grip.org/fr/siteweb/images/RAPPORTS/2002 /2002-01.pdf

${ }^{48}$ Lu Gang, "The Shanghai Cooperation Organization: A Successful Model for Regional Cooperation in the Twenty-First Century". English Edition of Qiushi Journal, vol. 5 núm. 1, 1 de enero de 2013, en http://english.qstheory.cn/international/201302/t20130227_213714.htm

${ }^{49}$ El objetivo de China es contrarrestar la penetración de Estados Unidos en la región, reforzar la influencia china, desempeñar un papel en la estabilización de las zonas fronterizas, y posiblemente presentar un nuevo modelo de relaciones internacionales que pudiera ser extendido al resto de Asia.

${ }^{50}$ Raquel Freire, Entrevista personal, Coimbra, 2012. Raquel Freire es profe- 
la autora especifica que ésta es "una lectura bastante negativa"; la sco es "un éxito" "motivado en gran parte por reacción a actores externos, en particular a Estados Unidos". ${ }^{51}$ Para Armando Guedes, los intereses de Beijing y Moscú dentro de la sco son tan divergentes que se trata de un "matrimonio de conveniencia" entre Rusia y China. ${ }^{52}$ Detrás de esta aparente unión de objetivos, se esconde una especie de "juego del gato y el ratón”, según Heitor Romana. ${ }^{53}$ Para este experto, existe hoy "un profundo debate a nivel de think tanks [rusos] sobre qué política energética debiera Rusia seguir respecto a China". ${ }^{54}$ En este contexto, "algunos argumentan que se debiera enfocar en aproximarse a China”, porque China es "un aliado estratégico [...] en lo que concierne relaciones económicas" y "por supuesto, respecto a la oferta energética de gas y petróleo". ${ }^{55}$ Otros estiman que "es peligroso" porque "genera una dependencia de la producción rusa hacia el mercado chino". ${ }^{56}$ Heitor Romana afirma que "en China, existe además la postura contraria", esto es, "si China elige a Rusia como socio privilegiado para el suministro de sus necesidades energéticas, estarían dependiendo de la ayuda rusa". ${ }^{57}$ En la práctica, según Romana "hay una desconfianza mutua respecto a los propósitos de uno y otro", y el autor cree que "es inevitable que Rusia se convierta en un proveedor preponderante de gas y petróleo para China en un futuro cercano". ${ }^{58} \mathrm{La}$ sco se beneficia del reconocimiento internacional que sus miembros han buscado conseguir. Beijing y Moscú desconfían el uno del otro, a pesar de que ambos comparten la percepción de que Estados Unidos es una amenaza para la

sora de relaciones internacionales de la Universidad de Coimbra (Portugal) y autora de varios artículos sobre estudios post-soviéticos.

${ }^{51}$ Loc. cit.

${ }^{52}$ Guedes, op. cit.

${ }^{53}$ Heitor Romana, Entrevista personal, Lisboa, 2010. Heitor Romana es profesor de relaciones internacionales de la Universidad IscSP de Lisboa.

${ }^{54}$ Loc. cit.

${ }^{55}$ Loc. cit.

${ }^{56}$ Loc. cit.

${ }^{57}$ Loc. cit.

${ }^{58}$ Loc. cit. 
estabilidad y la independencia regional. Esto es innegable, según Heitor Romana, quien observa en la nueva generación rusa, además de una apatía hacia el comunismo, "una cosa en común: aversión hacia Estados Unidos", porque cree que los "estadounidenses tienen un 'complejo misionario' y desean cambiar el mundo y ocupar Rusia”. 59

Según un experto local que pidió anonimato, "la sco es una organización en desarrollo" que "empezó como una pequeña entidad y ha crecido a lo largo del tiempo". Tenemos que subrayar que este experto cree que "[la sco] no es una organización coordinada” y en que, en lugar de cooperación, "prevalecen los intereses individuales y el principio generalizado de mantener a los estadounidenses fuera de la esfera de influencia regional". Por su parte, Armando M. Guedes cree que la sco es "una institución que no es muy eficaz en la forma en que maneja asuntos regionales", excepto por "despertar el interés de académicos, políticos y analistas militares al hecho de que la zona es un barril de pólvora" ${ }^{60}$ Otro experto, Roman Mogileski, se considera "escéptico" respecto a la Organización de Cooperación de Shanghái, aunque admite que "en una fase temprana, la sco fue útil entre Rusia y China porque "ambos tenían intereses similares": "quitar influencias occidentales de Asia Central”, lo que refuerza, directa o indirectamente, la noción de "éxito por razones negativas" mencionada más arriba, o sea éxito motivado por una reacción en contra de elementos externos. ${ }^{61}$ Otro experto local, Oleg Egorov, afirma sin ningún subterfugio que la sco "es una organización política que discute asuntos económicos, pero que no decide nada". ${ }^{62}$

${ }^{59}$ Loc. cit.

${ }^{60}$ Guedes, op. cit.

${ }^{61}$ Véase la cita anterior de Raquel Freire. Roman Mogilevski, Entrevista personal, Bishkek, 2012. Roman Mogilevski es Director Ejecutivo de CASE-Kirguistán y consultor (Banco Mundial, Banco Asiático de Desarrollo, EC, PNUd, y proyectos usaID). Además, este experto es Director Ejecutivo del Centro de Investigación Económica y Social - Kirguistán.

${ }^{62}$ Oleg Egorov, Entrevista personal, Almaty, 2011. Oleg Egorov es un experto en el Instituto de Economía, un departamento del Ministerio de Educación y Ciencia de Kazajistán. 
Aunque las repúblicas de Asia Central mantienen vínculos estrechos en política, economía, cultura, religión, tradición y etnicidad, sus relaciones son complejas y a veces contradictorias. Como destaca A. Cooley, desde 2008 la sco parece haber entrado en un periodo de crisis de crecimiento: no ha establecido objetivos positivos a largo plazo, no tiene prioridades claras y rehúsa discutir los desacuerdos subyacentes a las prioridades de sus miembros. ${ }^{63}$ Como puntualizan Peyrouse, Boonstra y Laruelle, en la práctica "la Organización no pudo coordinar acciones en contra del tráfico de drogas, o convertirse en un foro de discusión sobre el tema del agua [en Asia Central] a pesar de los llamados de Bishkek, Dushanbe y Tashkent". ${ }^{64}$ La "obsesión por el consenso" y por "mantener el statu quo" ha restado eficacia a la Organización, y podría quitarle su legitimidad en el futuro". ${ }^{65}$ A pesar de que Dushanbe, Bishkek y Tashkent usen la sco para mediar sus disputas e intereses sobre los recursos acuíferos de la región, "China siempre ha rehusado involucrarse en esos asuntos". ${ }^{66}$

Se debe hacer notar en Asia Central "la existencia de un traslape funcional entre mecanismos de seguridad -incluidos la Organización de Cooperación de Shanghái, la Organización del Tratado de la Seguridad Colectiva, el programa de la oTAN "Asociación para la Paz" - y la dificultad de coordinarlas". ${ }^{67}$ Es motivo de debate si la existencia de tantos instrumentos de seguridad en una región aumenta o disminuye su seguridad". ${ }^{6}$

Aunque la sco es un actor importante en Asia Central, todavía carece de la capacidad de resolver por sí mismo los desafíos más

63 Alexander Cooley, "The Stagnation of the sco: Competing Agendas and Divergent Interests in Central Asia”, PONARS Memo núm. 85, 2009.

${ }^{64}$ Sébastien Peyrouse, Jos Boonstra y Marlène Laruelle, International Relations and Security Network, 5 de marzo de 2013, en http://www.isn.ethz.ch/isn/e-Educati on/The-ISN-TACC, p. 5.

${ }^{65}$ Loc. cit.

${ }^{66}$ Michael Emerson y Jos Boonstra, "Into EurAsia - Monitoring the EU's Central Asia Strategy”, EU-Central Asia Monitoring, núm. 13, 2010, p. 43.

${ }^{67}$ Huasheng Zhao, op. cit., p. 297.

68 Ivan Safranchuk, "The Competition for Security Roles in Central Asia”. Russia in Global Affairs, núm. 1, enero-marzo de 2008. 
graves en la región, ${ }^{69}$ como "la crisis de gobierno" en las repúblicas exsoviéticas de Asia Central, la lenta recuperación de Afganistán, el futuro político incierto de Pakistán y la débil infraestructura económica para sostener la expansión del comercio regional. ${ }^{70}$ Según el Grupo de Crisis Internacional, "de forma callada pero continua, la infraestructura física básica de Asia Central -caminos, plantas de energía, hospitales y escuelas, y la última generación de expertos entrenados por los soviéticos que podían mantener operativas estas infraestructuras- está desapareciendo". ${ }^{71}$

Existe también la necesidad de definir el tipo de organización regional en la que se convertirá la sco en un futuro y determinar los aspectos prácticos de cómo y en qué áreas puede avanzar la organización para cumplir sus propósitos. ${ }^{72}$ Según Chinara Esengul, "[la sco] no es todavía, para efectos prácticos, una organización", a pesar de ser "una plataforma favorable para el debate". ${ }^{73}$ Para países pequeños como Kirguistán, la SCO "es una institución capaz de ayudar al país a cumplir sus propósitos a corto plazo". ${ }^{74}$ Otra ventaja de ser parte de la organización se relaciona directamente con la ayuda financiera china que pueden obtener sus miembros. En el caso de Kirguistán, "la mayoría de las inversiones chinas no se gestionan de manera bilateral", sino como "proyectos de la Organización de Cooperación de Shanghái”. ${ }^{75}$ Para Chinara

${ }^{69}$ Como la sco no se diseñó para ser una organización supranacional (lo que implicaría reducir la soberanía de sus miembros), no tiene una estructura militar definida como la Organización del Tratado de Seguridad Colectiva, que incluye la venta de equipo tecnológico a los Estados miembros. A pesar de la creación de un centro antiterrorista en Taskent en 2004 -la Estructura Antiterrorista Regional (RATs por sus siglas en inglés), diseñada para desarrollar estrategias comunes en el combate a los movimientos terroristas- cualquier dinámica de seguridad multilateral sigue siendo rudimentaria.

${ }^{70}$ Philip Shishkin, Central Asia's Crisis of Governance, Asia Society, 2012, p. 25.

71 International Crisis Group, 2011, en http://www.crisisgroup.org/en/regions/asia/central-asia/201-central-asia-decay-and-decline.aspx, p. 1.

72 Westlund, 2012, en http://atlantic-council.ca/from-security-to-development-the-evolution-of-the-shanghai-cooperation-organization/

${ }^{73}$ Chinara Esengul, Entrevista personal, Bishkek, 2012.

${ }^{74}$ Loc. cit.

${ }^{75}$ Loc. cit. 
Esengul, "la evolución de la Organización depende de la confianza que sea posible consolidar entre Rusia y China". ${ }^{76}$

Según Tomás Ambrosio, "la relación entre la sco y la democratización regional es importante". ${ }^{77} \mathrm{El}$ autor afirma que la sco parece reforzar los regímenes autocráticos de Asia Central porque permite "utilizar la cooperación multilateral y las organizaciones internacionales como defensa contra las tendencias democráticas regionales y globales". ${ }^{78}$ En este sentido, la sco puede ser vista como contrapeso frente a normas democráticas externas en Asia Central, al apoyar el mantenimiento del statu quo y, en consecuencia, la permanencia de regímenes autoritarios en la región.

\section{Organización de CoOperación Económica}

La Organización de Cooperación Económica (ECO por sus siglas en inglés) fue creada por Pakistán, Irán y Turquía en 1985, con el propósito de promover una cooperación económica, técnica y cultural entre sus Estados miembros. Después de la caída de la Unión soviética, Azerbaiyán, Afganistán y las cinco repúblicas de Asia Central se unieron a ella. La Organización de Cooperación Económica está dotada de cohesión cultural, ya que une todos los países islámicos no árabes de Asia Central y Occidental. ${ }^{79}$

Entre sus principales objetivos están "el desarrollo económico sustentable de sus Estados miembros, el desmantelamiento progresivo de las barreras comerciales y la promoción de comercio intrarregional, aumentar el papel de los países de la ECO en el crecimiento del comercio internacional, promover los recursos materiales de la región, avanzar en la cooperación regional para el control de drogas, promover la protección ambiental y ecológica,

${ }^{76}$ Loc. cit.

77 Thomas Ambrosio, "Catching the 'Shanghai Spirit': How the Shanghai Cooperation Organization Promotes Authoritarian Norms in Central Asia”, Europe-Asia Studies, vol. 60, núm. 8, 2008, p. 1322.

${ }^{78}$ Loc. cit.

79 Richard Pomfret, The Economics of Regional Trading Arrangements, Oxford, Clarendon Press, 1997. 
y fortalecer los lazos históricos y culturales entre las poblaciones de la región". ${ }^{80}$ Es interesante observar que "la Organización para la Cooperación Económica es, a la fecha, la única organización intergubernamental regional que incorpora todas las repúblicas de Asia Central como miembros permanentes". Además, es preciso subrayar que esta organización, al contrario de otras que analizaremos, no incluye a Rusia, y que, en general, su composición difiere de otros grupos regionales. ${ }^{81}$ La máxima autoridad de esta organización es el Consejo de Ministros, "compuesta de Ministros de Relaciones Exteriores y representantes ministeriales nombrados por sus respectivos gobiernos". ${ }^{82}$ El Consejo de Representantes Permanentes se compone de representantes permanentes y embajadores de los Estados miembros, y del Director General para Asuntos de ECo de cada Ministerio de Relaciones Exteriores. El Secretariado General incluye agencias especializadas y Consejos de Planeación Regionales.

La dimensión económica es el principal vector de cooperación dentro de la Organización de Cooperación Económica. En este sentido, sus Estados miembros han buscado hacer avances relevantes, respecto al tránsito de personas y bienes por ejemplo. ${ }^{83}$ No obstante, el multilateralismo no siempre ha producido resultados útiles dentro de la organización. Por un lado, hay algunos Estados miembros que prefieren tratar asuntos como visas "por medio de canales bilaterales, evitando de esta forma las reglas multilaterales". ${ }^{84}$ Más aún, se debe recordar que "todos los miembros de la Organización de Cooperación Económica están involucrados al mismo tiempo con otras organizaciones regionales" (creando de esta forma un traslape o conflicto de interés); este hecho puede ser, paradójicamente, otra limitante de la adopción de un enfoque multilateral, en el sentido de que el "exceso" de

${ }^{80}$ Laruelle y Peyrouse, op. cit., p. 17.

${ }^{81}$ Chinara Esengul, op. cit., p. 83.

${ }^{82}$ Laruelle y Peyrouse, op. cit., p. 17.

${ }^{83}$ ECO Annual Economic Report, 2010, en http://www.ecosecretariat.org/ ftproot/Publications/Annual_Economic_Report/2010/Annual\%20Economic\%20Report\%202010.pdf

${ }^{84}$ Chinara Esengul, op. cit., 2009, p. 88. 
multilateralismo puede ser contraproducente. ${ }^{85}$ Aunque sea prematuro decir que la cooperación dentro de la Organización de Cooperación Económica no es funcional por la cantidad de ambiciosos proyectos que faltan por cumplir, se puede subrayar la existencia de varias barreras para su operación. Linn y Pidufala refieren, por ejemplo, que "desde que la ECO no ha tenido recursos financieros, no ha podido apoyar inversiones significativas en infraestructura" ${ }^{86}$ Además, la organización está afrontando asuntos regionales importantes como la falta continua de transportes transnacionales y rutas de comunicación, el lento desarrollo de perspectivas para el comercio energético, la degradación ambiental extensiva resultado de la explotación de recursos (un ejemplo apremiante es el descenso en el volumen del Mar de Aral) y la inestabilidad en Afganistán (que permite tráfico de drogas y terrorismo). Más aún, como Schweickert y colaboradores notan, "la promoción de la integración comercial -uno de los objetivos centrales de la ECO- ha sido lento en la práctica" ${ }^{87}$ Basado en el "bajo resultado de la ECO para ratificar y/o implementar sus propias regulaciones y planes de acción", se debe mencionar que "los miembros de la Eco están en distintas etapas de desarrollo económico a causa de razones históricas y políticas", lo que dificulta "alinear los intereses económicos de todos los Estados miembros". 88 Además, aunque "las instituciones económicas estén en el corazón del marco institucional de la Organización de Cooperación Económica, no son capaces de impulsar una cooperación económica efectiva y atraer crecimiento económico y desarrollo" y, en general "la Organización de Cooperación Económica no ha logrado convertirse en un bloque económico importante". ${ }^{89}$ La organización carece de mecanismos para supervisar el estado de implementación y sancio-

85 Ibid., p. 90.

86 Johannes Linn y Oksana Pidufala, Lessons for Central Asia: Experience with Regional Economic Cooperation, Manila, Asian Development Bank, 2008, p. 8.

87 Rainer Schweickert et al., External Drivers of Institutional Change in Central Asia - Regional Integration Schemes and the Role of Russia and China, Kiel Institute for the World Economy, 2012, p. 16.

${ }^{88}$ Loc. cit.

${ }^{89}$ Chinara Esengul, op. cit., 2009, p. 89. 
nar Estados miembros que no cumplen las fechas límite. ${ }^{90}$ Además, "las relaciones dentro de la Eco siempre se han caracterizado por una rivalidad geopolítica entre algunos de sus Estados miembros (en particular entre Turquía e Irán) y por las actitudes diferentes de dichos Estados hacia actores externos -como Rusia, China y el Occidente- que también han influenciado en cómo los miembros de la Eco cooperan". ${ }^{11}$ Debe añadirse que la mayoría de los proyectos de la Organización de Cooperación Económica, para ser exitosos, requieren apoyo conjunto de Irán y Turquía. La cooperación entre ambos países es frágil, ya que Irán resiente la afinidad de Turquía hacia las potencias occidentales, en especial Israel. A pesar de estos obstáculos, debemos reconocer que la Organización de Cooperación Económica permite a las repúblicas de Asia Central diversificar su política exterior hacia el sur y el oeste, y beneficiar de la cooperación con Estados que tienen raíces culturales, religiosas y lingüísticas comunes.

\section{ORGANIZACIÓN DEL TRATADO DE LA SEGURIDAD COLECTIVA}

La Organización del Tratado de la Seguridad Colectiva (scTo por sus siglas en inglés) es "una organización regional liderada por Rusia definida como "OTAN del Este", porque fue creada como contrapeso frente a la influencia occidental en el antiguo espacio soviético (y también como contrapeso frente a la presencia china) ". ${ }^{92}$ La organización surgió de la Comunidad de Estados Independientes y del Tratado de Seguridad Colectiva (Tratado de Taskent), firmado por Armenia, Kazajistán, Kirguistán, Rusia, Tayikistán y Uzbekistán en 1992 (Georgia, Azerbaiyán y Bielorrusia se unieron en 1994).$^{93} \mathrm{La}$ organización tiene un Consejo Permanente de Seguridad Colectiva,

${ }^{90}$ Naribaev Marat, "The Republic of Kazakhastan and the Economic Cooperation Organization: Present State and Future Cooperation”, Central Asia and the Caucasus, vol. 1, núm. 49, 2008, pp. 98-112.

${ }^{91}$ Schweickert et al., op. cit., p. 16.

${ }^{92}$ Fabio Indeo, "Central Asia between National Interest and Supranational Projects”, Istituto di Alti Studi in Geopolitica e Scienze Ausiliarie, 2013, p. 5.

${ }^{93}$ Loc. cit. 
compuesto de jefes de Estado y representado por un Secretario General a cargo de tomar las decisiones y de asegurar la coordinación entre los Estados miembros. ${ }^{94}$ Los principales objetivos de la organización son asegurar la paz, preservar la integridad del territorio de los Estados miembros, coordinar el combate contra el terrorismo, tráfico de drogas y crimen organizado internacional, y proveer asistencia militar inmediata a los Estados miembros en caso de amenaza. El mandato de la Organización del Tratado de la Seguridad Colectiva no incluye intervención militar en caso de inestabilidad interna; ese argumento legal ha sido utilizado por Moscú para justificar no intervenir en los disturbios en Osh en el sur de Kirguistán en junio 2010.

Rusia ha buscado convertir a la organización en un instrumento más eficaz, expandiendo sus fuerzas bajo un comando común y aumentando sus bases militares en el territorio de las repúblicas asiáticas centrales. ${ }^{95}$ En este sentido, debe subrayarse el establecimiento en 2009 de un operativo -la Fuerza de Reacción Rápida Colectiva- que tuvo alrededor de 7000 soldados. ${ }^{96}$ Además, como menciona Roy Allison, "como Estado dominante en la csTo, Rusia claramente quiere usar la organización como una plataforma macro regional para apoyar su postura de 'gestor de seguridad' en Asia Central y confirmar el reconocimiento de la cSTO como, por lo menos, un actor en igualdad de condiciones en la región que la OTAN". ${ }^{97}$ Desde la formación de la CSTO, Rusia ha mostrado interés en que ambas organizaciones [la OTAN y la CSTO] coordinaran sus actividades contra el tráfico de drogas", no obstante "el escepticismo occidental del papel de Rusia en la cSTO y sus intenciones para la organización han desairado dicha cooperación hasta ahora". ${ }^{98}$

${ }^{94}$ John Mowchan, U.S. Army War College, 2009, en http:/ /www.csl.army.mil/ usacsl/publications/IP_6_09_Militarization_of_the_CSTO.pdf

95 Nikitina, 2012, en http://web.ebscohost.com/ehost/pdfviewer/pdfviewe r?sid=37123ad6-91dd-4729-a4c5-56ec9976f51f\%40sessionmgr114\&vid=3\&hid=108

${ }^{96}$ Vladimir Socor, "The csto: Missions, Capabilities, Political Ambitions", Eurasia Daily Monitor, vol. 6, núm. 25, 6 de febrero de 2009.

${ }^{97}$ Roy Allison, "Regionalism, Regional Structures and Security Management in Central Asia”, p. 471.

${ }^{98}$ Roy Allison, "Strategic Reassertion in Russia’s Central Asia Policy", Interna- 
A pesar de las expectativas rusas y de su compromiso con la organización, "la CSTO no ha sido hasta ahora tan eficaz como Rusia desearía que fuera, porque Bielorrusia y Uzbekistán rechazaron cooperar completamente desde el inicio". ${ }^{99}$

\section{Comunidad de Estados indePendientes}

La Comunidad de Estados Independientes (cis por sus siglas en inglés) fue la primera organización regional del periodo postsoviético. Fue creada por el Acuerdo de Minsk y el de Alma-Ata, con el objetivo de mantener la integración económica y de seguridad de la mayoría de las antiguas repúblicas soviéticas. El organigrama de la organización designa como cuerpo máximo al Consejo de Jefes de Estado, y hay otros tres cuerpos ejecutivos: el Comité Ejecutivo, el Consejo Económico y el Consejo de Representantes Permanentes de los Estados miembros. ${ }^{100}$ Aunque la organización "ha sido un vehículo para la "desintegración civil" de los militares [resultado de la caída de la Unión Soviética], falló en establecer un sistema de seguridad funcional". ${ }^{101}$ Las principales razones de esto son "diferencias en las orientaciones geopolíticas de los Estados miembros" o bien "la ausencia de una amenaza común y el miedo del neo-imperialismo ruso". ${ }^{102}$

Según Alexander Libman, "la Comunidad de Estados Independientes es actualmente sólo una vaga alianza, compuesta de varios países que se reúnen en reuniones más o menos periódicas, y varios proyectos de infraestructura y cooperación humanitaria”. ${ }^{103}$ Más aún, como subrayan Sakwa y Webber, el presupuesto

tional Affairs (Royal Institute of International Affairs 1944), vol. 80, núm. 2, 2004, p. 292.

${ }^{99}$ Schweickert et al., op. cit., p. 14.

${ }^{100}$ Sergei Voitovich, "The Commonwealth of Independent States: An Emerging Institutional Model”, EJIL, 1993, pp. 403-417.

101 Chinara Esengul, op. cit., pp. 58-59.

102 Ibid., p. 59.

103 Alexander Libman, "Commonwealth of Independent States and Eurasian Economic Community”, en G. Finizio et al. (eds.), The Democratization of Internatio- 
de la organización se limita a lo justo necesario para mantener su burocracia". ${ }^{104}$ Esto es consecuencia de la difícil situación económica de sus países miembros. ${ }^{105}$ Chinara Esengul considera por ello que "es demasiado pronto para siquiera hablar de un espacio económico común o de otras formas de intensa cooperación económica”. ${ }^{106}$ No obstante, esta experta señala que a pesar de los problemas económicos similares, hay grandes diferencias en el ámbito de contextos locales: los distintos grados de reformas económicas y liberalización, las diferencias en las cantidades de recursos naturales, y en consecuencia el potencial de tener políticas económicas independientes. Además, de regreso a Sakwa y Webber, estos autores subrayan la incapacidad de las instituciones de la Comunidad de Estados Independientes para proveer incentivos que promuevan la cooperación económica entre Estados. ${ }^{107}$ En resumen, "la Comunidad de Estados Independientes no se convirtió en una organización capaz de coordinar las preferencias políticas de sus miembros y proveer una postura común en ciertos asuntos de política exterior"; y "en lo que respecta la política interna de cada Estado miembro, la Comunidad de Estados Independientes ha evitado cualquier modelo ideológico y prescriptivo de buen gobierno". ${ }^{108}$

Respecto a la contribución de la Comunidad de Estados Independientes en el desarrollo del regionalismo en Asia Central, “[esta organización] ha generado más acuerdos insustanciales y retórica en asuntos de política de seguridad en Asia Central que cualquier otra estructura ostensiblemente multilateral". ${ }^{109}$ Las variaciones en localización geográfica, recursos y percepciones

nal Organizations: First International Democracy Report 2011, International Democracy Watch/Centre for Studies on Federalism, 2011, p. 44.

${ }^{104}$ Richard Sakwa y Mark Webber, “The Commonwealth of Independent States, 1991-1998: Stagnation and Survival”, Europe-Asia Studies, vol. 51, núm. 3, 1999, p. 384.

105 Kathleen Collins, "Economic and Security Regionalism among Patrimonial Authoritarian Regimes: The Case of Central Asia”, Europe-Asia Studies, vol. 61, núm. 2, 2009.

106 Chinara Esengul, op. cit., p. 60.

${ }^{107}$ Sakwa y Webber, op. cit.

108 Chinara Esengul, op. cit., p. 64.

${ }^{109}$ Roy Allison, "Regionalism, Regional Structures and Security Management in Central Asia”, p. 469. 
de amenaza de los Estados de Asia Central los han hecho resistir los esfuerzos rusos por jalar sus intereses hacia asuntos de mayor relevancia que aspectos limitados de soberanía para una integración de seguridad. ${ }^{110}$ Aunque la situación no ha cambiado desde el 11 de septiembre, "Rusia ha usado la bandera del combate al terrorismo en un esfuerzo energético por regenerar un sistema colectivo dentro de la cis en Asia Central y proveerla de cierta estructura institucional". ${ }^{111}$

\section{Comunidad Económica Eurasiática}

La Comunidad Económica Eurasiática (EurAsEC por sus siglas en inglés) se creó en 2000 a partir de la "iniciativa kazaja del presidente Nursultán Nazarbáyev e inspirada por el modelo de la Unión Europea". ${ }^{112}$ El órgano de mayor jerarquía para la toma de decisiones es el Consejo Interestatal, el cual se reúne al menos una vez por año en el nivel de jefes de Estado y dos veces al año en el nivel de jefes de Gobierno. El Comité de Integración constituye un cuerpo permanente de la Comunidad Económica Eurasiática, formado por "ministros de gobierno que se reúnen al menos cuatro veces al año". ${ }^{113}$ La Asamblea Interparlamentaria, basada en San Petersburgo, se compone de miembros delegados de parlamentos nacionales. El desarrollo inicial de la Comunidad Económica Eurasiática estaba estrechamente ligada a los esfuerzos de la Comunidad de Estados Independientes por mantener una cooperación económica intensa, como la que existía en la era soviética. ${ }^{114}$ Los

110 Olcott $e t$ al., "The Failure to Establish an Integrated Security Structure", en Getting It Wrong: Regional Cooperation and the Commonwealth of Independent States, Washington, D. C., Carnegie Endowment for International Peace, 1999.

${ }^{111}$ Roy Allison, "Regionalism, Regional Structures and Security Management in Central Asia", p. 470.

112 Laruelle y Peyrouse, op. cit., p. 10.

113 Ibid., p. 11.

${ }^{114}$ Richard Pomfret, "Chapters on Kazakhstan and on Tajikistan, Turkmenistan and Uzbekistan”, en K. Anderson y J. Swinnen (eds.), Distortions to Agricultural Incentives in Europe's Transition Economies, Washington, D. C., World Bank, 2008. 
principales objetivos de la organización eran: "alcanzar un régimen de libre comercio; crear una tarifa fronteriza unificada y un sistema de regulación unificado para mediciones fronterizas no-tarifarias; formar una mercado financiero común; coordinar los principios y las condiciones para la transición a una moneda común; abrir un mercado común de servicios de transporte y un sistema de transporte unificado; moldear un mercado energético común". ${ }^{115}$ La organización busca también "asegurar la movilidad total entre sus ciudadanos y coordinar la política social" para establecer "un mercado laboral común, un espacio educativo común y enfoques coordinados de asistencia médica y migración laboral". ${ }^{116}$ Aunque esta lista de objetivos es bastante ambiciosa y, en consecuencia, es prácticamente imposible cumplirlos todos, se debe notar que "la cooperación económica dentro de la Comunidad Económica Eurasiática parece llevarse con éxito en términos del número de interacciones entre Estados miembros". ${ }^{117}$

Como apuntan Schweickert y colaboradores, "El impacto de EurAsEC en la integración regional o en la cooperación puede ser bastante limitado". ${ }^{118}$ En efecto, según Chinara Esengul, "en el momento en que la organización es una estructura subregional dentro de un marco de cooperación más amplio de la Comunidad de Estados Independientes (CIS), tiene los mismos limitantes que la CIS y la Organización del Tratado de la Seguridad Colectiva”. ${ }^{119}$ Algunas iniciativas recientes asociadas a la Comunidad Económica Eurasiática, como "el Banco Eurasiático de Desarrollo", "probablemente van a tener éxito", mientras que proyectos más ambiciosos, como la Unión Aduanera, son cuestionables". ${ }^{120}$ Debe añadirse que la organización no tiene recursos presupuestarios propios para apoyar proyectos de infraestructura. El involucramiento de organizaciones no gubernamentales en asuntos de integración postsoviética es bastante limitado. Tanto la cis como la Comunidad Económica Eurasiática

\footnotetext{
115 Laruelle y Peyrouse, op. cit., p. 11.

${ }^{116}$ Loc. cit.

117 Chinara Esengul, op. cit., p. 73.

118 Schweickert et al., op. cit., p. 12.

119 Chinara Esengul, op. cit., p. 75.

${ }^{120}$ Libman, op. cit., p. 44.
} 
reflejan esta tendencia, ya que ambas son "herramientas de "integración protectora" usadas por regímenes semi-autoritarios para darse apoyo mutuamente en el área postsoviética". ${ }^{121}$ En consecuencia, "estas instituciones parecen ser concebidas más como mecanismos de coacción de libertades políticas que como plataformas para el desarrollo de la sociedad civil". Incluso "el impacto de la cis y de las instituciones de la Comunidad Económica Eurasiática en la democracia legal son por lo general negativas". ${ }^{122}$ También debe señalarse que "la legitimidad de la misión de la cis y de la Comunidad Económica Eurasiática es un tanto ambigua: aunque todavía existe un apoyo público generalizado hacia la integración, el funcionamiento de dichas instituciones se juzga de forma crítica; no obstante, aun los que consideran que la cis es ineficiente están en contra de su disolución". ${ }^{123}$

\section{Las RepÚblicas de Asia Central VIS-Ä-VIS El Regionalismo}

A partir del análisis de cinco organizaciones regionales (Organización de Cooperación de Shanghái, Organización de Cooperación Económica, Organización del Tratado de la Seguridad Colectiva, Comunidad de Estados Independientes y Comunidad Económica Eurasiática), concluimos que el regionalismo en Asia Central parece haber alcanzado un nivel bajo de cooperación e integración internacional. Según Roy Allison, "la debilidad del regionalismo en Asia Central relativo a seguridad [...] refleja factores fuera del control de los Estados locales". ${ }^{124}$ Primero, "el legado o la presencia de la influencia hegemónica rusa en la región, que puede llegar o no a ser desplazada por la proyección del poder hegemónico estadounidense en este contexto"; segundo, "el fenómeno relacionado del actuar competitivo de las potencias regionales y sus efectos diversos"; tercero, "las exhaustivas demandas puestas sobre los

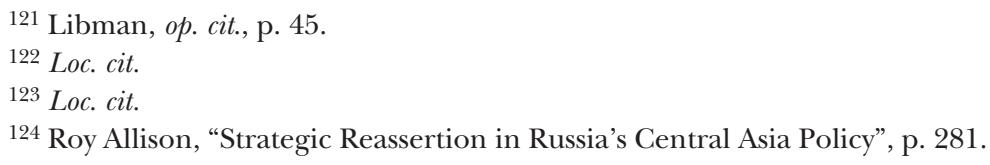


Estados locales por consolidar la soberanía nacional en una zona periférica del sistema global". ${ }^{125}$

Un aspecto fundamental que se desprende del análisis de las organizaciones mencionadas previamente es que "el regionalismo en Asia Central depende de forma considerable del papel de Rusia como líder regional”, más precisamente, "de qué tan benéficas son las acciones de Rusia respecto al desarrollo de la región; de qué tan flexible es Rusia para reconciliar los intereses de las organizaciones regionales más prometedoras (la Comunidad Económica Eurasiática y la Organización de Cooperación de Shanghái); y especialmente de la capacidad de las repúblicas de Asia Central para mantenerse unidas". ${ }^{126}$

Los esfuerzos de las repúblicas de Asia Central por desarrollar la cooperación mediante el uso de organizaciones multilaterales no han sido exitosos hasta la fecha, lo que no implica que la cooperación sea imposible. Por un lado, es prudente recordar que varias de estas organizaciones están en periodo de gestación, y que todavía les falta tiempo para estar completamente institucionalizadas, por lo que es necesario esperar (mayores) resultados sustantivos. ${ }^{127}$ Nicolas Contessi apunta que "las instituciones multilaterales son importantes en Eurasia, pero la cooperación multilateral depende considerablemente de relaciones de poder". ${ }^{128}$ Más aún, se debe apuntar que "el multilateralismo no es de ninguna manera la única herramienta, sino más bien un complemento al bilateralismo", el cual "sigue siendo muy importante" en la región. ${ }^{129}$

"Todos los intentos de crear instituciones regionales en las que sólo los cinco países de Asia Central son miembros han fracasado, sobre todo por falta de voluntad política", excepto por la

125 Roy Allison, "Regionalism, Regional Structures and Security Management in Central Asia", p. 481.

${ }^{126}$ Chinara Esengul, op. cit., pp. 76-77

127 Tom Moylan, 2013, "Regionalism in Central Asia", 28 de julio, e-internationak relations, en http://www.e-ir.info/2013/07/28/regionalism-in-central-asia/

128 Nicola Contessi, "China, Russia and the Leadership of the sco: A Tacit Deal Scenario”, China and Eurasia Forum Quarterly, vol. 8, núm. 4, 2010, p. 3

129 Nicola Contessi, op. cit., p. 11. 
Organización de Cooperación Económica. ${ }^{130}$ En efecto, múltiples tensiones entre líderes políticos dañan la cooperación regional, así como asuntos fronterizos no resueltos, orientaciones geopolíticas contradictorias y la incapacidad de encontrar resoluciones consensuadas al asunto de la energía y el agua. Según Fabio Indeo, "la falta de cooperación regional en los sectores económicos y energéticos, las amenazas del terrorismo islámico, el tráfico de drogas [...], los intentos fallidos de resolver problemas endógenos -como fronteras comunes o derechos de minorías- caracterizan el Asia Central postsoviética". 131

Durante los últimos veinte años, ha habido varias discusiones sobre la necesidad de integración regional -y no únicamente la necesidad de cooperación regional-, lo que es un reto considerable. Según Chinara Esengul, experta kirguís en asuntos de cooperación e integración en Asia Central, "es incuestionable que no hay cooperación en la región, ya sea en el tema de compartir recursos de agua, ya sea en el nivel de los acuerdos fronterizos, entre otros". ${ }^{132}$ Más aún, como explica esta autora, "no podemos hablar en los absoluto de integración”. ${ }^{133}$ Por su parte, Meruet Makhmatova menciona la existencia de "un número de iniciativas"134 desde la caída de la Unión Soviética cuyo propósito es "promover la cooperación en Asia Central". ${ }^{135}$ Hay otras instituciones no exclusivas de Asia Central pero a las cuales pertenecen varias o todas las repúblicas de Asia Central, como la Comunidad Económica Eurasiática, la Organización de Cooperación de Shanghái, la Comunidad de Estados Independientes, el Espacio Único Económico, la Organización

${ }^{130}$ Laruelle y Peyrouse, op. cit., p. 32.

${ }^{131}$ Fabio Indeo, "The Concept of a Greater Central Asia: Perspectives of a Regional Approach", CASI Working Paper, Presented at the First Annual CASI Conference at University of Camerino, 2011, p. 1.

132 Chinara Esengul, op. cit.

133 Loc. cit.

${ }^{134}$ Véase, por ejemplo, los "Tratados de Amistad Eterna" firmados por Kazajistán y Kirguistán, Kazajistán y Uzbekistán, Kirguistán y Uzbekistán, Kirguistán, y Tayikistán y Turkmenistán y Uzbekistán.

135 Meruert Makhmatova, Entrevista personal, Almaty, 2011. Meruert Makhmatova es un experto kazako y director del Centro de Investigación en Política Pública de Almaty. 
del Tratado de la Seguridad Colectiva, entre otras. No obstante, "la existencia de estos cuerpos" no ha sido eficaz para la cooperación entre Estados de la región, ya que ésta depende sobre todo de "ambiciones políticas de los presidentes [de los países de Asia Central]". ${ }^{136}$ Como resultado de los diferentes objetivos e intereses de quienes definen políticas regionales, "la Organización de Cooperación de Shanghái es, desafortunadamente, no más que un buen eslogan, recordado de vez en cuando". 137

En efecto, reconociendo que las repúblicas asiáticas centrales comparten una "historia común", M. Makhmatova subraya que no hay suficiente presión para que los Estados de la región formen un tipo de "Unión de Asia Central", quizás inspirado en el modelo europeo (la Unión Europea), por las "relaciones entre líderes políticos", sus "ambiciones" y "la estructura de las economías de Asia Central". ${ }^{138}$ En efecto, como explica Fabio Indeo, "la existencia de desconfianza entre los líderes de Asia Central”, más "interesados en asuntos internos" y en fortalecer su liderazgo que en "encontrar soluciones a problemas regionales", "la falta de cooperación en recursos energéticos entre países 'ricos' versus pobres", la "discrepancia entre objetivos políticos perseguidos por dos de las potencias regionales [Rusia y China], pueden ser "serias amenazas para la definición de una estrategia regional coherente y exitosa". ${ }^{139}$

Ser un país pequeño no significa necesariamente ser un país indefenso. Las repúblicas de Asia Central asumen una postura racional, buscando maximizar sus intereses dentro del "New Great Game”, en tanto poder funcional, expresión utilizada por Adriano Moreira. Según Luis Fontoura, ${ }^{140}$ Adriano Moreira se refería a los Estados "con alguna influencia en asuntos internacionales", resultado de un poder "por excepción (por ejemplo, localización geográfica, materias primas y recursos naturales estratégicos, entre otros)". Dicho poder da a los Estados una "capacidad

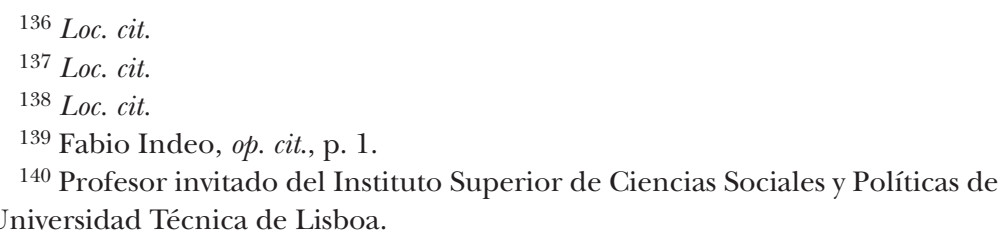


de intervención internacional superior a la que tendrían de no tomar en cuenta esas circunstancias, las cuales, al variar significativamente, pueden provocar cambios sustanciales en su importancia en el juego internacional". ${ }^{141}$ Yendo directamente a los escritos de Moreira, comprendemos el surgimiento del concepto de poder funcional "como el resultado de la situación aparentemente paradójica de que, conforme el poder de las potencias creció, y éstas disminuyeron en número, el número de poderes pequeños y de tamaño medio también aumentó, y esto ha aumentado su libertad de acción”. ${ }^{142}$ En este contexto, el poder funcional es, para Moreira, "un nuevo concepto operativo que puede ayudar al análisis de la situación en la que nos encontramos". Para el autor, el petróleo "es una base suficientemente importante y significativa" para explicar "que países nuevos en la escena mundial" sean capaces de "imponer sus condiciones a lo que queda de la soberanía occidental". ${ }^{143}$ Adriano Moreira caracteriza el poder funcional como "la capacidad de someter a las potencias, utilizando la función mundial realizada por los países interesados, a un grado de racionalidad que la práctica de la ética no ha conseguido". ${ }^{144}$ Dicho esto, las repúblicas asiáticas centrales, aunque geográficamente pequeñas, son una parte importante y capaz, paradójicamente, de frustrar las ambiciones de potencias extranjeras, como resultado de su poder funcional. Nótese, por ejemplo, el carácter singular de la política uzbeka, en algunas ocasiones pro-rusa, otras contraria a ella, lo que convierte a Karimov en un aliado impredecible, según los intereses que mejor se ajustan a Uzbekistán.

Para Estados pequeños como las repúblicas asiáticas centrales, la singularidad de instituciones como la sco estriba en la oportunidad que ofrece de "asociarse tanto a Rusia como a China" en "un contexto en el cual la presencia china quiebra cada vez más cualquier esfuerzo ruso para imponer asuntos no deseados en la

${ }^{141}$ Luís Fontoura, "O Poder na Relação Externa do Estado: A Equação de Cline”, Negócios Estrangeiros (Lisboa), vol. 11, núm. 2, 2006, p. 19.

142 Adriano Moreira, "Poder Funcional - Poder Errático", Nação e Defesa, año 4, núm. 12, 1979, pp. 13-28, p. 19.

143 Ibid., p. 17.

144 Ibid., p. 18. 
agenda de integración de los Estados de Asia Central”. Al mismo tiempo, "la presencia rusa provee igualmente tranquilidad sobre las políticas chinas y en consecuencia permite a la SCO actuar como un vehículo para incorporar intereses chinos a las respuestas comunes a desafíos de seguridad en Asia Central". ${ }^{145}$ Como evidencia de su poder funcional y su capacidad para influenciar la agenda de sus vecinos Rusia y China, "los Estados miembros de Asia Central guardan cierta capacidad de maniobra para promover sus propios intereses y dejar huella en la agenda de la SCO". ${ }^{146}$

Según Sean Kay, "las instituciones multilaterales importan en Eurasia, pero la cooperación multilateral es altamente contingente a las relaciones de poder". ${ }^{147}$ En el contexto de Asia Central, "Estados grandes han utilizado a las instituciones multilaterales para ejercer poder, y los Estados pequeños las han usado para constreñir a los grandes". Además, "los Estados también han usado estas instituciones para señalar sus intenciones y reforzar la identidad interna". ${ }^{148}$

Para evaluar cómo las potencias influyen en las relaciones multilaterales entre países de Asia Central, Ruth Deyermond defiende la existencia de un modelo de hegemonía multinivel en el cual un país hegemónico global, Estados Unidos, un país hegemónico regional, Rusia, un país aspirante a ser hegemónico a nivel subregional, Uzbekistán, y un país hegemónico emergente global y regional, China, coexisten en el marco de la política de seguridad de Asia Central. Según Deyermond, "donde los intereses de los distintos países hegemónicos coinciden, o por lo menos no entran en conflicto, este arreglo puede caracterizarse como un modelo de hegemonía con forma de matrioshka", en el cual "los intereses de las hegemonías conviven de manera pacífica y, cuando los intereses coinciden,

145 Roy Allison, "Regionalism, Regional Structures and Security Management in Central Asia", p. 478.

146 Loc. cit.

${ }^{147}$ Sean Kay, "Geopolitical constraints and institutional innovation: the dynamics of multilateralism in Eurasia”, en J. Sperling et al., Limiting Institutions? The Challenge of Eurasian Security Governance, Manchester University Press Manchester y Nueva York, 2003, p. 125.

148 Loc. cit. 
pueden formar alianzas". ${ }^{149} \mathrm{El}$ autor cree que una guerra por hegemonía en la región es muy improbable, porque el país hegemónico global (Estados Unidos) actúa como un contendiente regional y el país hegemónico regional (Rusia) no puede (o no quiere) imponer un desafío por la posición hegemónica global de su contendiente regional. Siguiendo a Deyermond, "el resurgimiento ruso en la región, asistido por su relación con Uzbekistán y China, y facilitado, irónicamente, por la implementación de uno de los aspectos hegemónicos de Estados Unidos (la promoción de la democracia y la "democracia mediante reforma") indica que la competencia es, sin embargo, un rasgo central de las relaciones dentro de la región”. ${ }^{150}$

Los recursos de agua como fuente de tensión regional

El agua, utilizada como símbolo para promover la identidad nacional, o para "fines ideológicos, sociales y políticos", es un recurso clave en Asia Central. La región era denominada por los griegos clásicos como Transoxiana, que literalmente significa "la tierra en el otro lado del río Oxus" (ahora llamado el Amu Daria). ${ }^{151}$ El tema del agua dirigió la mirada de la comunidad internacional a la región poco después de la declaración de independencia de las cinco repúblicas asiáticas centrales. ${ }^{152}$

Como menciona Anar Khamzayeva, "la gestión del agua en Asia Central ha sido una fuente sustancial de enemistad entre Estados en la región, en particular entre Kirguistán y Tayikistán por un lado, y Uzbekistán por el otro”. ${ }^{153}$ Esta es una situación compleja,

149 Ruth Deyermond, "Matrioshka Hegemony? Multi-levelled Hegemonic Competition and Security in Post-Soviet Central Asia", Review of International Studies, vol. 35, 2009, p. 151.

150 Ibid., p. 173.

151 Mark Dickens, “The Uzbeks", 1990, en http://www.oxuscom.com/Uzbeks.pdf, p.2.

152 Gilles Rudaz, "The Great Mountain Game: Regional Governance in Central Asia”, en Comparing Regional Environmental Governance in East Asia and Europe (EE-REG), Department of Geography \& Environment, Kioto, 2013.

${ }^{153}$ Anar Khamzayeva, "Water Resources Management in Central Asia”, Documentos CIDOB ASIA 25, 2009, p. 10. 
ahondada por las tensiones intra e interestatales sobre el sistema de distribución de agua. También se intensifica por el aumento exponencial en el uso del agua y su desperdicio, los niveles bajos de agua en las plantas hidráulicas y el deterioro del ecosistema acuático. ${ }^{154}$ Regresando a Khamzayeva, "la cuestión es cómo resolver problemas complejos de gestión colectiva (retos relacionados al medio ambiente y al sector agrícola) y desarrollar las "políticas del agua nacionales' al mismo tiempo". ${ }^{155}$ A la fecha, los Estados de la región han conseguido evitar hostilidades militares, aunque las relaciones permanecen tensas. Una gestión regional del agua eficaz requiere un compromiso sustantivo de las repúblicas asiáticas centrales, que establezca un pacto abierto y coherente para gobernar dichos recursos.

Según Beatrice Mosello, "la cooperación se ha dañado por la percepción de los Estados de la región de que los recursos de agua son un juego de suma cero", en el cual "la ganancia de unos pocos se logra mediante la pérdida de muchos”. ${ }^{156}$ Esta dinámica se determina por tres factores principales, a saber "el contexto político (la independencia de las cinco repúblicas de Asia Central y el frágil liderazgo de los gobiernos locales), el contexto social (tensiones entre distintos grupos étnicos) y el contexto económico (economía política orientada hacia la autosuficiencia y tensiones entre los sectores agrícola y energético en la región)" ${ }^{157}$ En consecuencia, los Estados han mostrado una propensión a acercar los temas del agua a la seguridad, convirtiéndolos en asuntos de seguridad nacional". ${ }^{158}$

La disolución de la Unión Soviética y de su sistema administrativo provocó varias disputas sobre el control del agua entre repúblicas

${ }^{154}$ David Muckenhuber, "Breaking the Dam: Water Politics in Central Asia”, Global Observatory, 2013, http://www.theglobalobservatory.org/component/myblog/breaking-the-dam-water-politics-in-central-asia/blogger/David\%20Muckenhuber/

${ }^{155}$ Anar Khamzayeva, op. cit., p. 10.

156 Beatrice Mosello, "Water in Central Asia: A Prospect of Conflict or Cooperation?”, 2008, en http://www.princeton.edu/jpia/past-issues-1/2008/9.pdf, p. 156

157 Loc. cit.

158 Barry Buzan et al., Security: A New Framework for Analysis, Londres, Lynne Rienner Publishers, 1998. 
de Asia Central". ${ }^{159}$ Es importante recordar que al momento de la independencia de las repúblicas asiáticas centrales, el vínculo entre los sistemas de gestión de agua en la región era tan intenso que nuevas fronteras y realidades políticas no fueron capaces de sobrescribir los lazos del pasado. ${ }^{160}$ Dice Christian Melis, experto de la Organización para la Seguridad y la Cooperación en Europa en temas de agua y energía en la región, que "los Estados río arriba (Kirguistán y Tayikistán) liberaban agua siguiendo 'un esquema agrícola', o sea, "durante el verano, el agua era drenada por motivos agrícolas hacia los Estados río abajo", mientras que en invierno era momento de rellenar las reservas". ${ }^{161}$ Por el contrario, los países río abajo proveían electricidad y petróleo a los países río arriba, en un intercambio que satisfacía las necesidades de todos. Pero con el colapso de la Unión Soviética, el modus operandi ha cambiado. En efecto, hoy el "esquema energético" ha destituido los antiguos "esquemas agrícolas", lo que implica "soltar agua durante el invierno, para producir electricidad y rellenar [las presas] durante el verano". ${ }^{62}$

Según Jeremy Allouche, la crisis del agua en Asia Central se debe "a la forma en que ha sido asignada y gestionada", ya que "no es una crisis de cantidad sino de distribución”. ${ }^{163}$ El problema, como mencionamos arriba, reside en el desbalance subyacente a la

${ }^{159}$ Aliya Tskhay \& Bruce White, Mis/Managing the Resources of Identity: Towards an Understanding of the Roots and Possible Solutions to the Water Management Crisis in Central Asia, 2012. Al mismo tiempo, el desarrollo económico de la Unión Soviética creó una degradación ambiental profunda, fenómeno conocido como "Síndrome del Mar de Aral”. La severa reducción del área y volumen del Mar de Aral es el símbolo más evidente de la negligencia soviética hacia la gestión de los recursos de agua en la región: varios expertos soviéticos consideraban al Mar de Aral "un error de la naturaleza”. Oleg Egorov, un experto kazajo, subraya la relevancia del tema ambiental, afirmando que "la región ha sido subvalorada por la falta de cuidado de varias compañías energéticas que operan en Asia Central”, quienes "ignoran por completo leyes locales, y contaminan gravemente el área”. Oleg Egorov, op. cit.

${ }^{160}$ Erika Weinthal, "Human Development Report - Water Conflict and Cooperation in Central Asia”. Human Development Report, Office Occasional Paper, 2006.

${ }^{161}$ Christian Mellis, Entrevista personal, Dushanbe, 2012.

162 Loc. cit.

163 Jeremy Allouche, "The Governance of Central Asian Waters: National Interests versus Regional Cooperation”, Disarmament Forum, 2007, p. 45. 
distribución de agua. ${ }^{164}$ Aunque las repúblicas de Asia Central firmaron, junto con otros países, "el Acuerdo Almaty de 1992" (ahora prescrito y por ello "dotado de efectividad limitada"), y decidieron "mantener la cuota de asignación de agua de la era soviética" (para salvaguardar la producción de algodón en los Estados río abajo), en la práctica cada país de la región ha tenido "su propia política del agua". ${ }^{165}$ Como afirma Chait, "la divergencia de intereses nacionales ha difuminado la voluntad política para priorizar objetivos regionales", y "la falta de consenso en un acuerdo mutuamente benéfico ha impedido una cooperación efectiva". ${ }^{166}$ Los países río abajo son favorables a mantener las cuotas de asignación de agua soviéticas, mientras que Kirguistán y Tayikistán piden pago por proveer recursos de agua a estos Estados río abajo.

El asunto del agua ha sido crecientemente percibido por países de la región como un "juego de suma cero". Debe añadirse que los Estados de la región están divididos sobre si el agua debe verse como un "bien común" o como una "mercancía". ${ }^{167}$ Dentro de este debate, los Estados río arriba han argumentado que "el agua debiera tratarse como una mercancía, y ser pagada por los Estados río abajo (cuando menos en lo que respecta el mantenimiento y costos de operación de presas y turbinas". ${ }^{68}$ Por el contrario, "los Estados río abajo han argumentado que ríos internacionales deben

${ }^{164} \mathrm{Al}$ momento de la independencia, los países río abajo tenían $82 \%$ del agua (Uzbekistán retiró 52\%, Turkmenistán 20\% y Kazajistán 10\%). Por el contrario, el total del agua retirada por países río arriba (Afganistán, Kirguistán y Tajikistan) fue sólo de $17 \%$.

${ }^{165}$ Luis Izquierdo et al., "Water Crisis in Central Asia: Key Challenges and Opportunities", Graduate Program in International Affairs, New School University, 2010, p. 7.

${ }^{166}$ Elisa Chait, "Water Politics of Syr Darya Basin, Central Asia: Question of State Interests", 2010, en http:/ / www.envsec.org/centasia/proj/ferghana/reports/ Chait.pdf, p. 1.

${ }^{167}$ Global Water Forum, 2010, en http:/ / www.globalwaterforum.org/2010/09/ 20/water-a-free-public-good-or-a-market-commodity/

${ }^{168}$ Johannes Linn, “The Impending Water Crisis in Central Asia: An Immediate Threat", 2008, en http://www.brookings.edu/research/opinions/2008/06/19central-asia-linn, párr. 4. 
ser vistos como un bien común compartido por todos los países de la región”. 169

Algunos apuntes sobre petróleo y gas

Un reporte especial, preparado por la región del Caspio y Asia Central, estima que "el total de las reservas de petróleo de la región supera los 60000 millones de barriles", y algunos estimados suben este número a "más de 200000 millones de barriles". ${ }^{170}$ Según Elaheh Koolaee y Masoud-Imani Kalesar, "se estima que el Caspio contiene de 2 a $4 \%$ de las reservas mundiales de hidrocarburos", lo que no se compara con las reservas del Golfo Pérsico pero sí "al potencial energético del Mar del Norte". ${ }^{171}$

Los recursos energéticos se reparten desigualmente en la región: Kazajistán y Azerbaiyán son los Estados con las mayores reservas de petróleo recuperable. Según el Reporte estadístico sobre la energía mundial de вP, en 2010 Azerbaiyán tenía siete millones de barriles de reservas comprobadas, lo que representa $0.5 \%$ de las reservas globales. ${ }^{172}$ Kazajistán, por su lado, tenía a finales de 2010 alrededor de 30000 millones de barriles de reservas comprobadas. ${ }^{173}$ Según un artículo de The Business Year, "Kazajistán tiene la undécima reserva más grande de petróleo en el mundo, y la segunda reserva después de Rusia entre los países de la Comunidad de Estados Independientes"; el país produjo "1.6 millones de barriles de petróleo por día en 2011”, convirtiéndolo en el décimo séptimo productor de petróleo en el mundo". ${ }^{174}$ La producción

${ }^{169}$ Luis Izquierdo et al., op. cit., p. 11.

170 Special Report: “Caspian Region”, Global Business Reports, 2012, en http://www.gbreports.com/admin/reports/Caspian_O\&G2012.pdf, p. 1.

${ }^{171}$ Elaheh Koolaee y Masoud Imani-Kalesar, "India's Energy Security Strategy Towards the Caspian Sea Region”, China and Eurasia Forum Quarterly, vol. 8, núm. 1, 2010, p. 86.

172 BP Statistical Review of World Energy, June 2012, en http:/ /www.bp.com/ statisticalreview

173 Loc. cit.

174 The Business Year, Year in Review - 2020 Vision, 2013, en http://www. 
de petróleo en Turkmenistán y Uzbekistán es relativamente insignificante, con la tendencia de llenar las necesidades internas de cada país. Según estimaciones de la Administración de la Información Energética de Estados Unidos, en 2012 “Uzbekistán tenía 594 millones de barriles de reservas petróleo comprobados y 171 yacimientos definidos de petróleo y gas, de las cuales 51 producen petróleo y 17 gas". ${ }^{175}$ Para Turkmenistán, la Administración de la Información Energética de Estados Unidos reporta que el país es todavía "un exportador de petróleo pequeño". En enero de 2012, el país tenía "600 millones de barriles de reservas de petróleo comprobadas". ${ }^{176}$

Según Global Business Reports, la región del Caspio "tiene reservas probadas de más de seis trillones de pies cúbicos”, la mayor parte de los cuales están en Turkmenistán y Uzbekistán. ${ }^{177}$ Según la Administración de la Información Energética, “Turkmenistán está hoy posicionado entre los seis países con mayores reservas de gas natural en el mundo, y entre los veinte mayores productores de gas a nivel mundial", con "reservas de aproximadamente siete trillones de metros cúbicos en 2012, un incremento considerable respecto a los dos trillones de metros cúbicos que tenía en 2009". ${ }^{178}$

Uzbekistán, por su parte, es uno de los mayores productores de gas natural de la Comunidad de Estados Independientes, "con alrededor de 1.8 trillones de metros cúbicos de reservas de gas comprobadas en 2012", lo que lo convierte en "el tercer productor de gas en la Comunidad de Estados Independientes y uno de los diez mayores en el mundo". ${ }^{179}$ Aunque sus reservas de petróleo no son significativas, el país es rico en gas y está dotado de una posición geográfica propicia para el tránsito energético de China y

thebusinessyear.com/publication/article/5/82/kazakhstan-2011/2020-vision, párr. 4.

175 U.S. Energy Information Administration, Uzbekistan Analysis Briefs, 2012, en http://www.eia.gov/countries/cab.cfm?fips=UZ, p. 1 .

${ }^{176}$ Loc. cit.

177 Global Business Reports, op. cit., p. 1.

178 Energy Information Administration, Country Analysis Briefs - "Turkmenistan", 2012, en http://www.eia.gov/countries/country-data.cfm?fips=tx, p. 4 .

${ }^{179}$ Loc. cit. 
Asia del sudeste. Además, según Michael Denison, "hay reservas energéticas prometedoras en la cuenca del Mar de Aral y el altiplano Ustyurt en Uzbekistán occidental que pueden conectarse fácilmente con la infraestructura de transporte regional". ${ }^{180}$

Kazajistán, donde según The Business Year había alrededor de dos trillones de metros cúbicos de reservas de gas (la décimo cuarta reserva del mundo), tiene la posición 27 entre los productores de gas en el mundo, habiendo producido 1300 millones de metros cúbicos en 2010. ${ }^{181}$ Siguiendo a AzerNews, la producción de gas en 2012 en Kazajistán aumentó 1.5\% respecto a 2011, el equivalente de 40100 millones de metros cúbicos. ${ }^{182}$ Según GIObserver, "Kazajistán es un importante país de tránsito para las exportaciones de gas de Uzbekistán y Turkmenistán a Rusia y China”. ${ }^{183}$

Dice Global Security: "Kirguistán tiene alrededor de 5.6 trillones de metros cúbicos de reservas de gas, aunque son difíciles de explorar técnicamente". Hoy en día, "Kirguistán no tiene el capital para infraestructura ni el financiamiento para aumentar la explotación de esta reserva de gas, y el país importa la mayor parte de su gas de Uzbekistán”. ${ }^{184}$ Esta relación comercial ha sido difícil para ambos países, considerando que Kirguistán retrasa los pagos seguido, lo que provoca que Uzbekistán suspenda el suministro de gas. Esto acarrea serios problemas en el invierno, porque el gas es usado tanto para calefacción como para producir electricidad.

Finalmente, se estima que Tayikistán tiene, como Kirguistán, "5.6 trillones de metros cúbicos de reservas de gas". ${ }^{185}$ En 2000, "Tayikistán comenzó a operar en el yacimiento de Khoja Sartez en

${ }^{180}$ Michael Denison, "The EU and Central Asia: Commercialising the Energy Relationship”, EUCAM Working Paper, núm. 2, 2009, p. 8.

181 The Business Year, op. cit.

182 AzerNews, 30 de enero de 2013, en http://www.azernews.az/oil_and_ gas/49040.html

${ }^{183}$ La mayor parte de las reservas de gas kazajas están en la región occidental del país, sobre todo en el campo de Karachaganak, para el cual se estiman "unas reservas probadas de aproximadamente 1 trillón de metros cúbicos”. GlObserver, op. cit., 2011, p. 1.

184 Global Security, 2013, en http://www.globalsecurity.org/military/world/ centralasia/tajik-energy.htm, párr. 4 .

185 Ibid., párr. 6. 
la región Kolkhozobod". ${ }^{186}$ Después de ilustrar la riqueza energética regional, y su potencial respecto al petróleo, el gas natural y los recursos hidroeléctricos, discutiremos brevemente cómo la existencia de estos recursos energéticos afecta e influencia la política regional, moldeada por la competencia entre actores extraregionales y regionales.

\section{Los componentes energéticos de la política regional}

La crisis financiera global y la teoría de que el agua será una de las próximas causas de conflicto han servido, en parte, para "ocultar un juego energético mundial de importancia fundamental y que ha sido silenciado". ${ }^{187}$ Este "juego" es una cruda disputa por el control de las reservas de petróleo y gas natural de Asia Central. Con el descubrimiento de nuevas reservas en Turkmenistán y Kazajistán, además de las reservas conocidas de Azerbaiyán, la región se ha convertido en un importante enclave energético. Por un lado, tenemos a "las potencias occidentales, lideradas por Estados Unidos, fuertemente dependientes del petróleo y gas natural"; por el otro, "la llegada de nuevos competidores, China y Rusia”. ${ }^{188}$ Se debe añadir Irán a esta ecuación, aspirante a convertirse en potencia regional. ${ }^{189}$

Esta región, que trasciende fronteras políticas y étnicas, "es un área reciente de competencia entre competidores nuevos y viejos" y "el juego se hará por medio de los ductos energéticos desde Asia Central al resto del mundo, aunque las rutas estén todavía en discusión". ${ }^{190}$ Cada competidor intenta, no obstante, defender su ruta preferida. Turkmenistán, Kazajistán y Azerbaiyán son Estados aislados, dependientes en consecuencia de sus vecinos para

186 Loc. cit.

187 Ambika Vishwanath, "The Energy Game”, 2010, en http://www.strategicforesight.com/inner-articles.php?id=185\#.UuCO_hCp1MsStrategic Foresight Gro up, párr. 1.

188 Loc. cit.

189 Alexandros Peterson, "Iran Looks to the North", 2013, en http://www.washingtontimes.com/news/2013/jul/18/iran-looks-to-the-north/

${ }^{190}$ Ambika Vishwanath, op. cit., párr. 2. 
drenar su gas y petróleo. Históricamente, el petróleo y gas natural han fluido desde Rusia a Europa y otros destinos; Moscú prefiere mantener el statu quo y controlar las ventas de recursos energéticos a los mercados europeos. ${ }^{191}$ Por su parte, Irán pretende cambiar esta tendencia, haciendo que los recursos vayan hacia el sur por su territorio, y exportarlos "a todo el mundo desde el Golfo Pérsico". ${ }^{192}$ China propone construir tres mil kilómetros de ductos de petróleo desde el Caspio pasando por Kazajistán; primero construyendo líneas más pequeñas para mantener la economía de este país y empezar a suministrar a otras economías asiáticas. ${ }^{193}$ Idealmente, "Estados Unidos, que no tiene acceso directo a los yacimientos de petróleo y gas natural [de Asia Central], argumenta que estos recursos consiguen colocarse en mercados abiertos sin estar sujetos a condicionantes de Rusia, China o Irán". ${ }^{194}$

En la periferia de este juego está Turquía. Con una posición privilegiada, Turquía tiene mucho que ganar como país de tránsito energético hacia Europa y, sobre todo, hacia Asia. Puede ser extremadamente útil y sabio en el largo plazo para los otros jugadores darse cuenta del potencial de este país estable e incluirlo en futuras negociaciones. También es muy importante reconocer que Asia será el mayor mercado energético en las siguientes décadas, y que cualquier país que participe en el control del flujo de energía hacia economías asiáticas participará también en el control de los mercados futuros. Una ruta vía Turquía tiene varias ventajas comparada con otras. ${ }^{195}$ Con buenas relaciones en la región, Turquía puede negociar rutas más viables política y estratégicamente que otras por medio de Rusia o China. El petróleo y gas embarcados en

191 Alexander Lande, "Russia's and the EU's Energy Security Discourses on Central Asia, A Frame Analytical Approach”, tesis, Faculty of Humanities, University of Oslo, 2011.

192 Ambika Vishwanath, op. cit., párr. 3.

193 Fabio Indeo, "Russia and China in Central Asia: Growing Geopolitical Competition”, ISPI Policy Brief, núm. 199, 2010.

${ }^{194}$ Ambika Vishwanath, op. cit., párr. 4.

195 Catherine Locatelli, "Russian and Caspian Hydrocarbons: Energy Supply Stakes for the European Union”, Europe-Asia Studies, vol. 62, núm. 6, 2010, pp. 959-971. 
Turquía pueden enviarse al mundo entero, "lo que posiblemente ofrecerá una alternativa al monopolio iraní en el Golfo Pérsico". ${ }^{196}$ Un ducto transcaspiano de Turkmenistán o Kazajistán hacia Turquía tiene menos complicaciones políticas que cualquier otra ruta, aunque los aspectos financieros y ambientales provocan múltiples cuestionamientos.

Por su situación de país interior, Asia Central depende de ductos de larga distancia, susceptibles de transportar petróleo y gas natural a mercados internacionales. ${ }^{197}$ Antes, los ductos de petróleo y gas soviéticos en la región conducían casi todos a Moscú. ${ }^{198}$ El control de esta infraestructura dio a Rusia influencia en el transporte de petróleo y gas natural de la región aún después del colapso de la Unión Soviética. ${ }^{199}$ Pero la inversión occidental en producción de petróleo y gas natural también provocó inversiones en nuevos ductos que no controlan Transneft (para petróleo) ni Gazprom (para gas). Estos nuevos ductos de petróleo y gas han disminuido el control ruso sobre el flujo de petróleo y gas natural del Cáucaso y Asia Central, y han contribuido a lograr los objetivos de la década de 1990: proveer más opciones económicas a la región, permitiendo que su producción petrolera y de gas natural se encaminara libremente hacia los mercados internacionales.

Es preciso señalar que "el concepto de guerras por recursos energéticos es a veces exagerado”. ${ }^{200} \mathrm{El}$ conflicto usualmente pospone inversiones a larga escala por muchos años. Es un hecho que "hay competencia por recursos en Asia Central, como lo hay en otras partes del mundo". ${ }^{201}$ The Newtimes. az subraya a este respecto: "la rivalidad entre Rusia, China y compañías de India del oeste

196 Ambika Vishwanath, op. cit., párr. 7.

197 Xuanli Liao, "Central Asia and China's Energy Security”, China and Eurasia Forum Quarterly, vol. 4, núm. 4, 2006, pp. 61-69.

${ }^{198}$ Edward Morse, "Russia and the Caspian States in the global energy balance”, Baker Institute Policy Report, núm. 39, 2009.

199 Zvi Magen y Olena Bagno-Moldavsky, "The Big Game: The Great Powers in Central Asia and the Caucasus", Strategic Assesment, vol. 12, núm. 4, 2010, pp. 115-126. ${ }^{200}$ Edward Chow, “The Emerging Threat of Resource Wars”, 2013, en http:/ / www.csis.org, párr. 5

${ }^{201}$ Joshua Kucera, 2013, en http://www.eurasianet.org/node/67303, párr. 4. 
[compañías petroleras] es incuestionable". ${ }^{202}$ No obstante, "lo que debiera preocupar a los expertos no es tanto el tema de potenciales guerras por recursos, sino que la competencia por estos esté basada en reglas, sin coerción política o prácticas de negociación no transparentes". ${ }^{203}$ Si las reglas de competencias son justas, las distintas compañías petroleras interesadas en Asia Central pueden competir de forma sana, y este tipo de competencia puede beneficiar a todos los actores involucrados en términos de promover eficiencia económica. La cooperación multilateral en los sectores energéticos es benéfica para "el desarrollo económico, la seguridad energética y la estabilidad regional”. ${ }^{204}$ En el futuro, "China, Rusia y las repúblicas de Asia Central debieran tomar ventaja de los mercados y sus recursos para expandir la cooperación para el desarrollo en el sector del gas, a partir del cual se puede mejorar y extender la cooperación en otros sectores para lograr un desarrollo común balanceado". ${ }^{205}$ A pesar de sus intereses y estatus económico diferentes, "Es improbable que Beijing y Moscú se involucren en un feroz enfrentamiento por los hidrocarburos de Asia Central". ${ }^{206} \mathrm{Al}$ contrario, hay evidencia de que las compañías chinas y rusas cooperan razonablemente bien a nivel corporativo.

La observación de la competencia por recursos energéticos, como petróleo y gas natural, y la respectiva evaluación de sus consecuencias, es compleja; sin embargo, según Edward Chow, "podemos esperar que en Asia Central el control por los recursos de agua tenga el potencial de provocar mayores conflictos que el petróleo y el gas natural". ${ }^{207}$ Debemos considerar otras dificultades

202 "Central Asia: New War on the Horizon?", 2013, en http://newtimes.az/ en/economics/2013/\#.UtLQRRCYZMs, párr. 5.

${ }^{203}$ Edward Chow, op. cit., 2013, párr. 5.

${ }^{204}$ Feng Dan, "Analysis on Natural Gas Geo-politics in Central Asia-Russia Region”. 21st World Energy Congress, 2010, en http://www.worldenergy.org/documents/congresspapers/140.pdf, p. 10.

205 Loc. cit.

206 Shamil Yenikeyeff, "BP, Russian Billionaires, and the Kremlin: A Power Triangle That Never Was", Oxford Energy Comment. 23 de noviembre de 2011, p. 75. ${ }^{207}$ Edward Chow, op. cit., 2013, párr. 5. 
que surgen, según Neil Brown, "de la falta de consenso sobre la división del Caspio", divergencias que posiblemente "afecten directamente a Asia Central". ${ }^{208}$ Debe apuntarse que "el juego se ha vuelto más complicado, con múltiples actores provenientes de distintas partes del mundo". ${ }^{209}$ Según Chow y Hendrix, "los principios del juego de suma cero aplican no sólo al caso de Rusia, China o Irán, sino también a la política de los gobiernos occidentales respecto a los ductos de gas y petróleo en Asia Central". ${ }^{210}$ Estos autores tienen cierta esperanza de que en la década siguiente haya más respecto por la geo-economía que por la geopolítica.

\section{Apuntes finales}

Aunque en el proceso histórico las disputas interestatales por el control de los recursos de agua han llevado raramente a la guerra, sí han propiciado décadas de tensiones regionales, limitado el desarrollo económico y arriesgado conducir a mayores conflictos. En este respecto, Johannes F. Linn predice el surgimiento de "crisis humanitarias, económicas y políticas graves en la región” -por tensiones alrededor del agua y la energía-, lo que posiblemente cause "conflictos transfronterizos en el ámbito comunitario y local". 211 En un artículo llamado "¿La línea frontal? Del sudoeste de los Balcanes a Asia Central”, Armando M. Guedes predice escenarios llenos de tensión, en los cuales "el petróleo y el gas están lado a lado y son los únicos bienes de consumo por los cuales se esforzarán los Estados necesitados". ${ }^{212}$ Por el contrario, según este experto, el agua es quizás el único recurso por el cual quien lo necesita seguro

208 Neil Brown, "Changing the Rules in Global Resource", 25 de julio de 2013, en http://www.docs.house.gov, párr. 10.

${ }^{209}$ Edward Chow y Leigh Hendrix, "Central Asia's Pipelines: Field of Dreams and Reality", The National Bureau of Asian Research, NBR Special Report \#23, 2010, p. 40 .

${ }^{210}$ Loc. cit.

${ }^{211}$ Linn, op. cit., 2008.

212 Armando Guedes, “A 'Linha da Frente'. Do Sudoeste dos Balcãs à Ásia Central”, Geopolítica, vol. 1, Centro Português de Geopolítica, Lisboa, 2007, p. 129. 
peleará. La explosión demográfica de poblaciones cada vez más empoderadas y difíciles de controlar, aunado a un clima tan árido como rico en recursos naturales codiciados por el resto del mundo, sólo puede sugerir turbulencias en los años siguientes, en esta línea de confrontación oriental ya tensa.

Los mayores temas y retos que afrontan las repúblicas asiáticas centrales dependen de una cooperación que, hasta la fecha, no ha existido en la práctica. A este hecho complejo por cuenta propia debemos añadir la interdependencia de las principales líneas de debate en la región. En otras palabras, como dice un experto local que pidió anonimato, "no podemos resolver el problema de la electricidad o de la energía sin resolver el asunto del agua". Al mismo tiempo, este asunto no puede resolverse por la desconfianza entre países de la región. A la pregunta de si las organizaciones regionales de Asia Central son o han sido capaces de actuar como mediadores en conflictos interestatales, Annette Bohr argumenta que las élites gobernantes de Asia Central tienen el siguiente dilema: “¿cómo reconciliar la necesidad, por un lado, de liberalizar y coordinar sus sistemas políticos y económicos para prevenir una mayor marginalización con, por el otro lado, la exigencia percibida de consolidar y mantener sus bases de poder?". ${ }^{213}$ Este dilema explica parcialmente por qué estructuras regionales que funcionan apenas han sobrevivido por años en Asia Central, dando sólo magros resultados y logros limitados. Además, como menciona Roy Allison, "la búsqueda de evidencia de una integración más profunda, que sugiera que los Estados de Asia Central están encaminados a forjar una comunidad de seguridad, es fútil", aunque "han hecho algunos esfuerzos por formar una plataforma regional común [...] para tratar temas de seguridad". ${ }^{214}$

Dicho esto, y aunque hayamos comenzado esta conclusión prediciendo escenarios de tensión regionales (característicos de los postulados realistas) como resultado de una división entre

213 Annette Bohr, "Regionalism in Central Asia: New Geopolitics, Old Regional Order", International Affairs, vol. 80, núm. 3, 2004, pp. 493-494.

${ }^{214}$ Roy Allison, "Regionalism, Regional Structures and Security Management in Central Asia”, p. 473. 
los intereses de los países, así como de rivalidades inherentes a los recursos hidroeléctricos, petroleros y de gas natural, no hemos excluido una vía intermedia, es decir, una concepción constructivista del regionalismo en Asia Central. Aunque todavía tímido (como hemos argumentado en este artículo), un escenario de mayor cooperación puede evolucionar en el futuro, porque los países deben tratar retos regionales que requieren respuestas colectivas. En consecuencia, creemos que el diagnóstico realista sobre las tensiones en el regionalismo de Asia Central es correcto, pero insuficiente. Paradójicamente, este enfoque carece de una visión constructivista, porque el comportamiento de los Estados no es fijo y no se determina por una racionalidad mecánica, sino por avances y retrocesos constantes, por lo que requiere una hermenéutica, es decir, un entendimiento que sólo el enfoque constructivista puede aportar. La vía para el regionalismo en Asia Central está abierta, fruto de la esencia inpredecible de la geopolítica.

\section{Bibliografía}

Allison, Roy, "Regionalism, Regional Structures and Security Management in Central Asia”, International Affairs, vol. 80, núm. 3, 2004, pp. 463-483.

—, "Strategic Reassertion in Russia's Central Asia Policy", International Affairs (Royal Institute of International Affairs 1944), vol. 80, núm. 2, 2004, pp. 277-293.

Allouche, Jeremy, "Water Nationalism - An Explanation of the Past and Present Conflicts in Central Asia, The Middle East and the Indian Subcontinent”, tesis, Université de Genève, núm. 699, 2005.

, "The Governance of Central Asian Waters: National Interests versus Regional Cooperation”, Disarmament Forum, 2007.

Ambrosio, Thomas "Catching the 'Shanghai Spirit': How the Shanghai Cooperation Organization Promotes Authoritarian Norms in Central Asia”, Europe-Asia Studies, vol. 60, núm. 8, 2008, pp. 1321-1344.

Asimov, Samuel, "Description of the Project", UNESCO History of Civilizations of Central Asia, 2001, en http://www.unesco.org/culture/ asia/html_eng/projet.htm 
AzerNews, 30 de enero de 2013, en http://www.azernews.az/oil_and_ gas/49040.html

Blank, Stephen, "U.S. Interest in Central Asia and Their Challenges", $D e-$ mokratizatsiya, abril de 2007.

Blank, Stephen, Entrevista personal, Estados Unidos, 2011.

Bohr, Annette, "Regionalism in Central Asia: New Geopolitics, Old Regional Order”, International Affairs, vol. 80, núm. 3, 2004, pp. 485-502.

Bouchard, Caroline y John Peterson, "Conceptualising Multilateralism: Can We All Just Get Along?”, E-paper, Mercury, núm.1, enero de 2011. BP Statistical Review of World Energy, June 2012, en http:/ /www.bp.com/ statisticalreview

Brauch et al., "Facing Global Environmental Change: Environmental Energy, Food, Health and Water Security Concepts", Hexagon Series on Human and Environmental Security and Peace, vol. 4, 2009, pp. 449-762.

Brown, Neil, "Changing the Rules in Global Resource", 25 de julio de 2013, en http://www.docs.house.gov

Brzezinski, Zbigniew, The Grand Chessboard: American Primacy and Its Geostrategic Imperatives, Nueva York, Basic books, 1997.

Buzan, Barry et al., Security: A New Framework for Analysis, Londres, Lynne Rienner Publishers, 1998.

“Central Asia: New War on the Horizon?", 2013, en http://newtimes.az/ en/economics/2013/\#.UtLQRRCYZMs

Chait, Elisa, "Water Politics of Syr Darya Basin, Central Asia: Question of State Interests", 2010, en http://www.envsec.org/centasia/proj/ferg hana/reports/Chait.pdf

"China offers $\$ 10$ billion loan to sco", China Daily, 16 de junio de 2009, en http://www.chinadaily.com.cn/china/2009sco/2009-06/16/content_8289602.htm

Chow, Edward, “The Emerging Threat of Resource Wars”, 2013, en http:/ / www.csis.org

Chow, Edward y Leigh Hendrix, "Central Asia's Pipelines: Field of Dreams and Reality", The National Bureau of Asian Research, NBR Special Report \#23, 2010.

Clarke, Michael, Bloomberg BusinessWeek, 26 de mayo de 2010, en http:/ / www.businessweek.com/stories/2010-05-26/chinas-deepening-ties-with-central-asiabusinessweek-business-news-stock-marketand-financial-advice\#disqus_thread 
Collins, Kathleen, "Economic and Security Regionalism among Patrimonial Authoritarian Regimes: The Case of Central Asia", Europe-Asia Studies, vol. 61, núm. 2, 2009.

Congressional Record 1998. "U.S. Interests in the Central Asian Republics Hearing Before the Subcommittee on Asia and the Pacific of the Committee on International Relations", House of Representatives One Hundred Fifth Congress Second Session (Statement of John Maresca, Vice President of International Relations, Unocal Corporation).

Contessi, Nicola, "China, Russia and the Leadership of the sco: A Tacit Deal Scenario”, China and Eurasia Forum Quarterly, vol. 8, núm. 4, 2010. Cooley, Alexander, "The Stagnation of the sco. Competing Agendas and Divergent Interests in Central Asia”, PONARS Memo núm. 85, 2009.

Denison, Michael, "The EU and Central Asia: Commercialising the Energy Relationship”, EUCAM Working Paper, núm. 2, 2009.

Deyermond, Ruth, "Matrioshka Hegemony? Multi-levelled Hegemonic Competition and Security in Post-Soviet Central Asia", Review of International Studies, vol. 35, 2009, pp. 151-173.

Dickens, Mark. "The Uzbeks", 1990, en http://www.oxuscom.com/Uzbe ks.pdf

Downs, Erika, "Inside China, Inc: China Development Bank's Cross-Border Energy Deals", John L. Thornton China Center Monograph Series, núm. 3, 2011.

Duarte, Paulo, "China looks to Central Asia", Boletim Mundorama, núm. 63, 2012.

ECO Annual Economic Report, 2010, en http:/ /www.ecosecretariat.org/ ftproot/Publications/Annual_Economic_Report/2010/Annual\%20 Economic\%20Report\%202010.pdf

Egorov, Oleg, Entrevista personal, Almaty, 2011.

Emerson, Michael \& Boonstra Jos, "Into EurAsia - Monitoring the EU's Central Asia Strategy”, EU-Central Asia Monitoring, núm. 13, 2010.

Energy Information Administration, Country Analysis Briefs - "Turkmenistan”, 2012, en http://www.eia.gov/countries/country-data.cfm?fi $\mathrm{ps}=\mathrm{tx}$

Esengul, Chinara, The Politics of Regionalism in Central Asia, Ministry of Education and Science of the Kyrgyz Republic, The Jusup Balasagyn Kyrgyz National University, 2009. , Entrevista personal, Bishkek, 2012. 
Eshchanov, Bahtyior, "How to Meet the Future Energy Needs of Uzbekistan”, tesis, Estocolmo, 2006.

Facon, Isabel, Les relations stratégiques Chine-Russie en 2005: la réactivation d'une amitié pragmatique, Fondation pour la Recherche Stratégique, 2006.

Feigenbaum, Evan, "The Shanghai Cooperation Organization and the Future of Central Asia", The Nixon Center, Washington, 2007, en http://2001-2009.state.gov/p/sca/rls/rm/2007/91858.htm

Feng Dan, "Analysis on Natural Gas Geo-politics in Central Asia-Russia Region”. 21st World Energy Congress, 2010, en http://www.worldenergy.org/documents/congresspapers/140.pdf

Ferdinand, Peter, "Sunset, Sunrise: China and Russia construct a New Relationship", International Affairs, vol. 83, núm. 5, 2007.

Fonseca, Pedro, Entrevista personal, Lisboa, 2011.

Fontoura, Luís, "O poder na relação externa do Estado: A Equação de Cline”, Negócios Estrangeiros (Lisboa), vol. 11, núm. 2, 2006.

Freire, Raquel, Entrevista personal, Coimbra, 2012.

Germanovich, Genee, "The Shanghai Cooperation Organisation: A Threat to American Interests in Central Asia?", China and Eurasia Forum Quarterly, vol. 6, núm. 1, 2008.

Global Security, 2013, en http://www.globalsecurity.org/military/world/ centralasia/tajik-energy.htm

GlObserver, June 25, 2011, en http://globserver.cn/en/kazakhstan/natural-gas

Global Water Forum, 2010, en http:/ /www.globalwaterforum.org/2010/ 09/20/water-a-free-public-good-or-a-market-commodity/

Granit, Jakob et al., Regional Water Intelligence Report Central Asia, SIWI, Estocolmo, 2010.

Guedes, Armando, “A 'Linha da Frente'. Do Sudoeste dos Balcãs à Ásia Central”, Geopolítica, vol. 1, Centro Português de Geopolítica, Lisboa, 2007.

— Entrevista personal, Lisboa, 2011.

Hoffman, David, Entrevista personal, Almaty, 2011.

Huasheng Zhao, "Central Asia in China's Diplomacy," en Eugene B. Rumer, Dmitriy Trenin y Huansheng Zhao (eds.), Central Asia: The View from Washington, Moscow, and Beijing, Nueva York, M. E. Sharpe, 2007.

Hurriyet Daily News, "China Puts Mark on Eurasia Energy Picture", 8 de 
septiembre de 2010, en http:/ /www.hurriyetdailynews.com/n.php?n= china-puts-its-mark-on-eurasia-energy-picture-2010-09-06

Indeo, Fabio, "Russia and China in Central Asia: Growing Geopolitical Competition”, ISPI Policy Brief, núm. 199, 2010.

_ , "The Concept of a Greater Central Asia: Perspectives of a Regional Approach", CASI Working Paper, Presented at the First Annual CASI Conference at University of Camerino, 2011.

, "Central Asia between national interest and supranational projects”, Istituto di Alti Studi in Geopolitica e Scienze Ausiliarie, 2013.

International Crisis Group, 2011, en http://www.crisisgroup.org/en/regions/asia/central-asia/201-central-asia-decay-and-decline.aspx

International Relations and Security Network, March 4, 2013, en http:// www.isn.ethz.ch/isn/Digital-Library/Articles/SpecialFeature/Detail $/$ ?lng=en\&id $=160464 \&$ contextid $774=160464 \&$ contextid $775=$ $160462 \&$ tabid $=1454180197$

Ismailov, Eldar y Vladimer Papava, Rethinking Central Eurasia, Central AsiaCaucasus Institute \& Silk Road Studies, 2010.

Izquierdo, Luis et al., "Water Crisis in Central Asia: Key Challenges and Opportunities", Graduate Program in International Affairs, New School University, 2010.

Kacowicz, Arie, "Regionalization, Globalization, and Nationalism: Convergent, Divergent, or Overlapping?", Working Paper 262, Kellog Institute, 1998.

Kay, Sean, "Geopolitical Constraints and Institutional Innovation: The Dynamics of Multilateralism in Eurasia", en J. Sperling et al., Limiting Institutions? The Challenge of Eurasian Security Governance, Manchester University Press Manchester y Nueva York, 2003.

Kellner, Thierry, "La Chine et la Nouvelle Asie Centrale", Rapport du GRIP 2002/1, Bruselas, GRIP, en http://archive.grip.org/en/siteweb/images/RAPPORTS/2002/2002-01.pdf

Khamzayeva, Anar, Water Resources Management in Central Asia : Regional and International Issues at Stake, Barcelona, СIDOB, 2009, 100 pp. (Documentos CIDOB ASIA, núm. 25)

Koolaee, Elaheh y Masoud Imani-Kalesar, "India's Energy Security Strategy Towards the Caspian Sea Region", China and Eurasia Forum Quarterly, vol. 8, núm. 1, 2010, pp. 83-94.

Kucera, Joshua, 2013, en http://www.eurasianet.org/node/67303 
Laruelle, Marlène y Sébastien Peyrouse, "The Chinese Question in Central Asia: Domestic Order, Social Change, and the Chinese Factor", 2012, en http:/ / cup.columbia.edu/book/978-0-231-70304-8/the-chi nese-question-in-central-asia]

Lande, Alexander, "Russia's and the EU's Energy Security Discourses on Central Asia, A Frame Analytical Approach", tesis, Faculty of Humanities, University of Oslo, 2011.

Lewis, Martin y Kren Wigen, The Myth of Continents: A Critique of Metageography, Berkeley, University of California Press, 1997.

Libman, Alexander, "Commonwealth of Independent States and Eurasian Economic Community", en G. Finizio et al. (eds.), The Democratization of International Organizations: First International Democracy Report 2011, International Democracy Watch/Centre for Studies on Federalism, 2011.

Linn, Johannes, "The Impending Water Crisis in Central Asia: An Immediate Threat", 2008, en http://www.brookings.edu/research/opinio ns/2008/06/19-central-asia-linn

_ , "Central Asian Regional Integration and Cooperation: Reality or Mirage?”, en Evgeny Vinokurov (ed.), EDB Eurasian Integration Yearbook, Almaty, Eurasian Development Bank, 2012, pp. 96-117.

Linn, Johannes y Oksana Pidufala, Lessons for Central Asia: Experience with Regional Economic Cooperation, Manila, Asian Development Bank, 2008.

Liu, Morgan, "Central Asia in the Post-Cold War World", Annual Review of Anthropology, vol. 40, 2011, pp. 115-131.

Locatelli, Catherine, "Russian and Caspian Hydrocarbons: Energy Supply Stakes for the European Union”, Europe-Asia Studies, vol. 62, núm. 6, 2010, pp. 959-971.

Lu Gang, "The Shanghai Cooperation Organization: A Successful Model for Regional Cooperation in the Twenty-First Century", English Edition of Qiushi Journal, vol. 5, núm. 1, 1 de enero de 2013, en http:/ / english.qstheory.cn/international/201302/t20130227_213714.htm

Macfarlane, Neil, "The United States and regionalism in Central Asia", International Affairs, vol. 80, núm. 3, 2004, pp. 447-461.

Mackinder, Halford, Democratic Ideals and Reality, Nueva York, Norton, 1962.

Magen, Zvi y Olena Bagno-Moldavsky, "The Big Game: The Great Powers in Central Asia and the Caucasus”, Strategic Assesment, vol. 12, núm. 4, 2010, pp. 115-126. 
Makhmatova, Meruert, Entrevista personal, Almaty, 2011.

Malik, Hafeez, Central Asia: Its strategic importance and future prospects, Nueva York, St. Martin's Press, 1994.

Mellis, Christian, Entrevista personal, Dushanbe, 2012.

Mogilevski, Roman, Entrevista personal, Bishkek, 2012.

Moreira, Adriano, "Poder Funcional - Poder Errático", Nação e Defesa, año 4, núm. 12, 1979, pp. 13-28.

Morgenthau, Hans, Politics Among Nations: The Struggle for Power and Peace, Nueva York, Alfred A. Knopf, 1948.

Morse, Edward, "Russia and the Caspian States in the Global Energy Balance”, Baker Institute Policy Report, núm. 39, 2009.

Mosello, Beatrice, "Water in Central Asia: A Prospect of Conflict or Cooperation?”, 2008, en http://www.princeton.edu/jpia/past-issues-1/ 2008/9.pdf

Moylan, Tom, 2013, "Regionalism in Central Asia”, July 28, e-internationak relations, en http://www.e-ir.info/2013/07/28/regionalism-in-central -asia/

Mowchan, John, U.S. Army War College, 2009, en http://www.csl.army. mil/usacsl/publications/IP_6_09_Militarization_of_the_CSTO.pdf

Muckenhuber, David. "Breaking the Dam: Water Politics in Central Asia", Global Observatory, 2013, http://www.theglobalobservatory.org/component/myblog/breaking-the-dam-water-politics-in-central-asia/ blogger/David\%20Muckenhuber/

Nanay, Julia, "Inside Track: sco Gaining Importance”, The National Interest online, 8 de agosto de 2007.

Naribaev Marat, "The Republic of Kazakhastan and the Economic Cooperation Organization: Present State and Future Cooperation", Central Asia and the Caucasus, vol. 1, núm. 49, 2008, pp. 98-112.

Nikitina, 2012, en http://web.ebscohost.com/ehost/pdfviewer/pdfview er?sid=37123ad6-91dd-4729-a4c5-56ec9976f51f\%40sessionmgr114\&vi $\mathrm{d}=3$ \&hid $=108$

Olcott, Martha, Aslund, Anders y Shermann Garnett, "The Failure to Establish an Integrated Security Structure”, en Getting It Wrong: Regional Cooperation and the Commonwealth of Independent States, Washington, D. C., Carnegie Endowment for International Peace, 1999.

Ottinger, Richard, UNEP Handbook for Drafting Laws on Energy Efficiency 
and Renewable Energy Resources, United Nations Environment Programme, 2007.

Peterson, Alexandros, "Iran looks to the north", 2013, en http:/ / www.was hingtontimes.com/news/2013/jul/18/iran-looks-to-the-north/

Peyrouse, Sébastien, "Central Asia's Growing Partnership with China, EU”, Central Asia Monitoring Working Paper, núm. 4, 2009.

Peyrouse, Sébastien, Jos Boonstra y Marlène Laruelle, International Relations and Security Network, 5 de marzo de 2013, en http://www.isn. ethz.ch/isn/e-Education/The-ISN-TACC

Peyrouse, Sébastien y Marlène Laruelle, China as a Neighbor: Central Asian Perspectives and Strategies, Central Asia-Caucasus Institute \& Silk Road Studies Program, 2009.

Pomfret, Richard, The Economics of Regional Trading Arrangements, Oxford, Clarendon Press, 1997.

—_, "Chapters on Kazakhstan and on Tajikistan, Turkmenistan and Uzbekistan”, en K. Anderson y J. Swinnen (eds.), Distortions to Agricultural Incentives in Europe's Transition Economies, Washington, D. C., World Bank, 2008.

Romana, Heitor, Entrevista personal, Lisboa, 2010.

Rudaz, Gilles, "The Great Mountain Game: Regional Governance in Central Asia", in Comparing Regional Environmental Governance in East Asia and Europe (EE-REG), Department of Geography \& Environment, Kioto, 2013.

Rumsfeld, Donald, "China-Russia Drill No Threat", China Daily, 2005, en http:/ / www.chinadaily.com.cn/english/doc/2005-08/25/content_472093.htm

Ruggie, John, "Epistemology, Ontology, and the Study of International Regimes", en Constructing the World Polity: Essays on International Institutionalization, Londres-Nueva York, Routledge, 1998.

Safranchuk, Ivan, "The Competition for Security Roles in Central Asia", Russia in Global Affairs, núm. 1, enero-marzo de 2008.

Sakwa, Richard y Mark Webber, "The Commonwealth of Independent States, 1991-1998: Stagnation and Survival", Europe-Asia Studies, vol. 51, núm. 3, 1999, pp. 379-415.

Schweickert, Rainer et al., External Drivers of Institutional Change in Central Asia - Regional Integration Schemes and the Role of Russia and China, Kiel Institute for the World Economy, 2012. 
Shenker, Jack, 2010, en http://www.prospectmagazine.co.uk/magazine/ karakalpakstan-aral-sea-nationalism-emigration/

Shishkin, Philip, Central Asia's Crisis of Governance, Asia Society, 2012.

Socor, Vladimir, "The csto: Missions, Capabilities, Political Ambitions", Eurasia Daily Monitor, vol. 6, núm. 25, 6 de febrero de 2009.

Special Report: “Caspian Region”, Global Business Reports, 2012, en http://www.gbreports.com/admin/reports/Caspian_O\&G2012.pdf Spykman, Nicholas, Estados Unidos frente al mundo, México, FCE, 1944.

Swanström, Niklas, China and Greater Central Asia: New Frontiers?, Central Asia - Caucasus Institute \& Silk Road Studies Program, 2011.

The Business Year, Year in Review - 2020 Vision, 2013, en http://www. thebusinessyear.com/publication/article/5/82/kazakhstan-2011/2020-vision

Tskhay, Aliya y Bruce White, "Mis/Managing the Resources of Identity: Towards an Understanding of the Roots and Possible Solutions to the Water Management Crisis in Central Asia”, The International Symposium on CD in Geneva 2012, 11 pp.

U.S. Energy Information Administration, Uzbekistan Analysis Briefs, 2012, en http://www.eia.gov/countries/cab.cfm?fips=UZ

Vayrynen, Raimo, "Regionalism: Old and New", International Studies Review, vol. 5, 2003, pp. 25-51.

Vishwanath, Ambika, "The Energy Game", 2010, en http://www.strategicforesight.com/inner-articles.php?id=185\#.UuCO_hCp1MsStrategic Foresight Group

Voitovich, Sergei, "The Commonwealth of Independent States: An Emerging Institutional Model”, EJIL, 1993, pp. 403-417.

Water Security and the Global Water Agenda, UN-Water Analytical Brief, 2013.

Weinthal, Erika, "Human Development Report - Water Conflict and Cooperation in Central Asia", Human Development Report, Office Occasional Paper, 2006.

Wendt, Alexander, "Anarchy Is what States Make of It: The Social Construction of Power Politics", International Organisation, vol. 46, núm. 2, 1992.

Westlund, 2012, en http://atlantic-council.ca/from-security-to-development-the-evolution-of-the-shanghai-cooperation-organization/

Winters, Alan, "Regionalism versus Multilateralism", Research Working Paper, 1996. 
Wolf, Aaron, "Transboundary Waters: Sharing Benefits, Lessons Learned. Thematic Background Paper", Bonn, International Conference on Freshwater, 2001, en http://www.water-2001.de/co_doc/transboundary_waters.pdf

Xiaojie Xu, Unlocking the Assets: Energy and the Future of Central Asia and the Caucasus Oil and Gas Linkages between Central Asia and China: A Geopolitical Perspective, The James A. Baker III. Institute for Public Policy of Rice University, 1999.

Xuanli Liao, "Central Asia and China's Energy Security", China and Eurasia Forum Quarterly, vol. 4, núm. 4, 2006, pp. 61-69.

Yenikeyeff, Shamil, "BP, Russian Billionaires, and the Kremlin: A Power Triangle That Never Was", Oxford Energy Comment, 23 de noviembre de 2011. 